\title{
Regeneration of Goldfish Retina: Rod Precursors Are a Likely Source of Regenerated Cells
}

\author{
PAMELA A. RAYMOND, ${ }^{1,2 *}$ MICHAEL J. REIFLER, ${ }^{2}$ \\ and PATRICIA K. RIVLIN ${ }^{2}$ \\ ${ }^{1}$ Neuroscience Program and ${ }^{2}$ Department of Anatomy and Cell Biology, The University of \\ Michigan Medical School, Ann Arbor, Michigan 48109-0616
}

Received July 13, 1987; accepted February 10, 1988

\section{SUMMARY}

This study describes regeneration of the neural retina in juvenile goldfish. The retina was destroyed with an intraocular injection of ouabain, a technique introduced by Wolburg and colleagues (Maier and Wolburg, 1979; Kurz-Isler and Wolburg, 1982). We confirmed their observation that the level of damage produced by the toxin was graded, in that neurons in the inner retinal layers were preferentially destroyed, and only in the more severely affected retinas were cells in the outer nuclear layer (i.e., photoreceptor cells) damaged. Evidence of retinal regeneration could be seen beginning about 2 weeks after the injection of ouabain. In contrast to previous studies (Maier and Wolburg, 1979), we found that regeneration took place only in those retinas in which photoreceptors had been destroyed. In cases in which the outer nuclear layer was spared, no regeneration of inner layers occurred, even after 6 months. Thymidine autoradiography was used to document the regeneration of new retinal neurons and to show that rod precursors, like other dividing cells, were not destroyed by the ouabain, but in contrast showed an increased mitotic activity. Regeneration did not proceed uniformly, but was initiated at neurogenic foci scattered across the retina. These foci consisted of clusters of dividing neuroepithelial-like cells. The evidence is consistent with the proposal that these cells were derived from rod precursors. These results imply that rod precursors are capable of a wider range of developmental fates than they normally express.

\section{INTRODUCTION}

Regeneration of the neural retina has been described in amphibians and fish, although most studies have been done on urodele amphibians (Keefe, 1973a,b; Reyer, 1977; Stroeva and Mitashov, 1981). Only a few studies have used teleost fish. For example, Lombardo $(1968,1972)$ reported that following surgical removal of one quadrant of the neural retina in goldfish, the retina

* To whom correspondence should be addressed at the Department of Anatomy and Cell Biology. P. A. Raymond published previously under the name P. R. Johns. 
regenerated over a period of several months. Easter et al. (1986) observed retinal regeneration in goldfish following removal of small $\left(1-4 \mathrm{~mm}^{2}\right)$ pieces. Wolburg and colleagues (Maier and Wolburg, 1979; Kurz-Isler and Wolburg, 1982) demonstrated regeneration of the retina in goldfish and trout following intravitreal injection of the metabolic poison, ouabain, a cardiac glycoside that inhibits $\mathrm{Na}^{+}, \mathrm{K}^{+}$-ATPase (Schwartz et al., 1975). Both Wolburg's group and Lombardo described two sites of enhanced mitotic activity during regeneration: at the retinal margin among cells of the germinal zone and in the outer nuclear layer. This observation was of interest to us because previous work, our own (Johns and Fernald, 1981; Johns, 1982) and that of others (Sandy and Blaxter, 1980), had shown that during normal postembryonic growth of the retina in teleost fish, cells proliferate in the same two places. The proliferating cells in the outer nuclear layer are rod precursors; that is, they give rise exclusively to new rod photoreceptors during normal retinal growth. The proliferating cells in the germinal zone are less specialized, in that they produce new retinal cells of all types. The germinal cells at the retinal margin are therefore pluripotent, whereas those in the outer nuclear layer have a restricted lineage, at least in intact retinas. Previous workers were unaware that the intact retina contained mitotic rod precursors, so they were uncertain as to the source of dividing cells in the outer nuclear layer of regenerating retinas. Kurz-Isler and Wolburg (1982) speculated that photoreceptors may have dedifferentiated and reentered the mitotic cycle, under the influence of degenerative and/or regenerative changes taking place in the retina. A more likely hypothesis given our current knowledge about rod precursors is that the mitotic activity observed in the outer nuclear layer during retinal regeneration represents enhanced proliferation in this population of cells.

We undertook the present study to ask the following questions: Is mitotic activity stimulated in rod precursors when the retina is damaged? Do rod precursor cells contribute to the process of retinal regeneration, and, if so, are they capable of producing other types of retinal neurons in addition to rods? Our results suggest that the answer to both questions is yes. Some of this work has been presented in preliminary communications (Raymond et al., 1986; Raymond, 1987).

\section{MATERIALS AND METHODS}

\section{Animals}

Goldfish (Carassius auratus) were obtained from a local pet store or were raised in the laboratory. Breeding stock was purchased from Ozark Fisheries (Richland, MO), and these fish were maintained throughout the year in the laboratory in a physiological state conducive to breeding (Raymond, 1985). Embryos and larval animals were reared as described previously (Johns, 1982; Raymond, 1985). The fish selected for these experiments were $3-4 \mathrm{~cm}$ standard body length, and the nasotemporal diameter of the eye ranged from 2.8 to $4.2 \mathrm{~mm}$, measured in situ with a caliper. From our initial experiments we found that the volume of the eye was critically important in determining the extent of damage following intraocular injection of the toxin, so in later experiments we attempted to standardize the dosage given to all fish by adopting a strict criterion for the size of the eye. Most of the results described here are from fish with eye diameters of $3.5 \pm 0.1 \mathrm{~mm}$. Fish obtained from the pet store were of unknown age; laboratory-reared animals were 6-13 months old. 


\section{Ouabain Injections}

Fish were anesthesized in $0.2 \%$ tricaine methanesulfonate (Sigma), wrapped in wet tissue, and placed on the stage of a Wild stereomicroscope. A small incision was made with a microknife (Micro-Sharp, Beaver, Inc., Waltham, MA) through the sclera at the limbus on the nasal side of the eye. A Hamilton microliter syringe was used to inject $1 \mu \mathrm{L}$ of ouabain, at a concentration of 1.4 $\mu M$ to $1.4 \mathrm{~m} M$ in $0.9 \%$ saline, into the posterior chamber. The concentration of ouabain in the eye was estimated subsequently as described below. In control experiments, in which the ouabain was replaced with a solution of methylene blue, we determined that backflow of the solution out of the hole was minimized by leaving the needle in the eye for approximately $10 \mathrm{~s}$ after the injection and then slowly withdrawing it. The left eye of each fish served as a control. In the initial experiments the left eye was injected with the vehicle alone $(0.9 \%$ saline $)$. In the remainder, the left eye was intact.

The intraocular concentration of ouabain was estimated for each fish after the eye was removed for histological processing. The external diameter of the globe was measured with a caliper; the lens was removed and its diameter was measured. Since both lens and eyeball are approximately spherical (Easter et al., 1977), the volumes of globe and lens could be readily calculated. The internal fluid volume of the eye was assumed to be the difference between the two (volume of globe minus volume of lens). The amount of ouabain injected was divided by the intraocular fluid volume of the eye to arrive at an estimate of the intraocular concentration. This estimate assumes that the ouabain diffused throughout the ocular tissues. The concentration of ouabain in the vitreous humor, before diffusion into the retina and other tissues, would have been about $30 \%$ higher than the values reported here, taking into account the thickness of the eyeball (about 300 $\mu \mathrm{m}$ at the limbus).

\section{Histological Processing}

At various times after ouabain injection ( 1 day to 6 months), fish were deeply anesthetized as above, killed by decapitation, and enucleated. The lenses were removed, and the eyes were immersed in fixative (Rivlin and Raymond, 1987) overnight at $4^{\circ} \mathrm{C}$. The following day, they were bisected along the dorsoventral axis, rinsed in buffer, dehydrated, and embedded in methacrylate resin (Sorvall). Sections, $3 \mu \mathrm{m}$ thick, were prepared from the cut surface of one of the two halves of each eye and stained as described previously (Johns, 1982). Every other slide was bleached with potassium permanganate/oxalic acid (Johns, 1982) to decolor the melanin in the pigmented retinal epithelium.

TABLE 1

Summary of Damage Produced by Ouabain

\begin{tabular}{|c|c|c|c|c|c|c|c|c|c|c|}
\hline & \multicolumn{10}{|c|}{ Estimated Intraocular [Ouabain] } \\
\hline & \multirow{2}{*}{$\frac{\times 10^{-8} M}{\leq 5.0}$} & \multicolumn{4}{|c|}{$\times 10^{-7} M$} & \multicolumn{4}{|c|}{$\times 10^{-6} M$} & \multirow{2}{*}{$\frac{\times 10^{-5} M}{\leq 5.0}$} \\
\hline & & $\leq 1.0$ & $\leq 2.5$ & $\leq 5.0$ & $\leq 7.5$ & $\leq 1.0$ & $\leq 2.5$ & $\leq 5.0$ & $\leq 7.5$ & \\
\hline No Cell loss & 3 & 3 & 6 & 5 & 1 & 4 & & & & \\
\hline $\begin{array}{l}\text { Loss of Inner } \\
\text { Retinal } \\
\text { Layers }\end{array}$ & & & & & & 19 & 2 & 3 & & \\
\hline $\begin{array}{c}\text { Loss of All } \\
\text { Retinal } \\
\text { Layers }\end{array}$ & & & & & & 16 & 2 & 4 & & \\
\hline Lethal & & & & & & & & & & 4 \\
\hline
\end{tabular}

Note: The numbers in the table represent the number of retinas at a given molar concentration of ouabain which were judged on histological examination to be damaged at the indicated level. Retinas were processed $1,2,3$, or 7 days after injection. The 4 fish at $\leq 5.0 \times 10^{-5} \mathrm{M}$ died within 24 $h$ after the injection. 

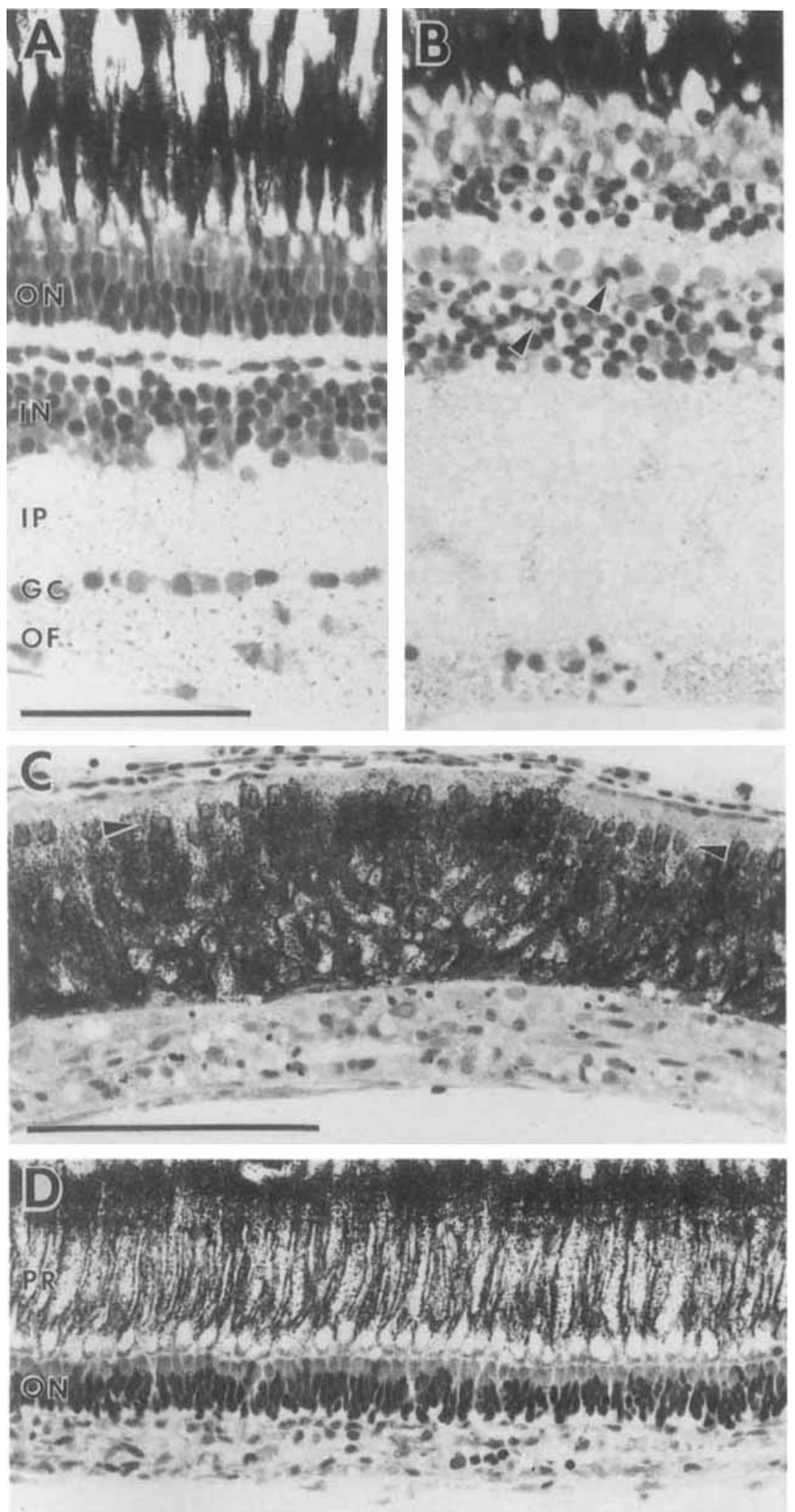
For some eyes, one-half was processed for light microscopic histology as described above, and the other half was prepared for electron microscopy. After aldehyde fixation, blocks were postfixed in osmium tetroxide/potassium ferricyanide and processed as described previously (Rivlin and Raymond, 1987).

\section{Thymidine Autoradiography}

We used thymidine autoradiography to demonstrate the sites of active cell proliferation during retinal regeneration and to identify the source of stem cells.

To follow the progress of retinal regeneration, ${ }^{3} \mathrm{H}$-thymidine was administered at various intervals $(1,2$, or 3 weeks) after the ouabain injection. In some fish the radionucleotide was injected intraocularly in the right (regenerating) eye, as described below. In other fish the label was injected intraperitoneally ( $4 \mu \mathrm{Ci} \times 3$ or 4 injections in a $24-\mathrm{h}$ period). The intraperitoneal injections were used when we wished to compare labeling indicies between regenerating and intact retina. If we did not intend to make such a comparison, we chose the intraocular route in order to minimize the amount of thymidine injected (Cleaver, 1967). Survival times in both groups ranged from 1 to 8 days. We showed previously that cells labeled after a few days are dividing; labeled cells that remain a week later have begun to differentiate (Raymond and Rivlin, 1987).

Another goal was to determine whether rod precursors survived after ouabain. Because rod precursors divide in the intact retina, they can be labeled with ${ }^{3} \mathrm{H}$-thymidine. This is not a selective marker for rod precursors, of course, since all dividing cells incorporate thymidine. In order to label a large fraction of the dividing population, fish were given 4 intraocular injections of ${ }^{3} \mathrm{H}$-thymidine $(1 \mu \mathrm{Ci}$ in $1 \mu \mathrm{L}$ sterile saline, specific activity $98 \mathrm{Ci} / \mathrm{mmol}$, New England Nuclear) spaced over a 12-24-h period. The following day, the same eye was injected with ouabain. Fish were sacrificed 1,3 , or 7 days later, and the eyes were processed for light microscopic or electron microscopic autoradiography as described previously (Johns, 1982; Raymond and Rivlin, 1987).

\section{${ }^{3} H$-ouabain Binding Sites}

To determine where in the retina ouabain-binding sites were lacated, we injected ${ }^{3} \mathrm{H}$-ouabain in place of the unlabeled ligand. Fish were injected intraocularly with $1 \mu \mathrm{L}$ of $30 \mu M^{3} \mathrm{H}$-ouabain (22.1 $\mathrm{Ci} / \mathrm{mmol}$, New England Nuclear) using the technique described above. This dose was comparable to that shown to cause partial or complete retinal damage (see Results). After 4 or $24 \mathrm{~h}$, fish were anesthetized, decapitated, and enucleated. The lens was removed, and the eyecup was quickly frozen in liquid freon cooled in liquid nitrogen. Frozen eyes were freeze-dried overnight under vacuum in a chamber cooled in a slush of dry ice in acetone (Ernst and Mills, 1980). The eyes were then fixed with $\mathrm{OsO}_{4}$ vapor in a dessicator overnight at room temperature, infiltrated with Spurr resin, and embedded. Sections, $0.5 \mu \mathrm{m}$ thick, were processed for autoradiography with NTB-2 emulsion (Eastman-Kodak, Rochester, NY). Slides were exposed at $4^{\circ} \mathrm{C}$ for 3 weeks to 3 months, developed in D-19 (Eastman-Kodak), and counter-stained in toluidine blue or Lee's stain (Johns, 1982).

\section{Morphometrics}

To characterize the regenerative response of the retina, we quantified the extent of damage and subsequent regeneration in representative retinas at $2-10$ weeks after injection. The control

Fig. 1. Degeneration of goldfish retina following intraocular injection of ouabain. (A) Control retina, injected with vehicle alone: outer nuclear layer (ON), inner nuclear layer (IN), inner plexiform layer (IP), ganglion cell layer (GC), optic fiber layer (OF). (B) 1 day after ouabain injection. Note the swollen inner plexiform layer and the pyknotic nuclei (arrowheads). (C) Another retina 1 day after ouabain injection. The cellular lamination was completely destroyed in the neural retina, but the row of pigmented epithelial cells (arrowheads) remained intact. (D) In this retina, 1 week after ouabain injection, only the inner layers were destroyed, but the outer nuclear layer and photoreceptor processes (PR) were preserved. Bars: A, $50 \mu \mathrm{m}$ (also applies to B); C, $100 \mu \mathrm{m}$ (also applies to D). 

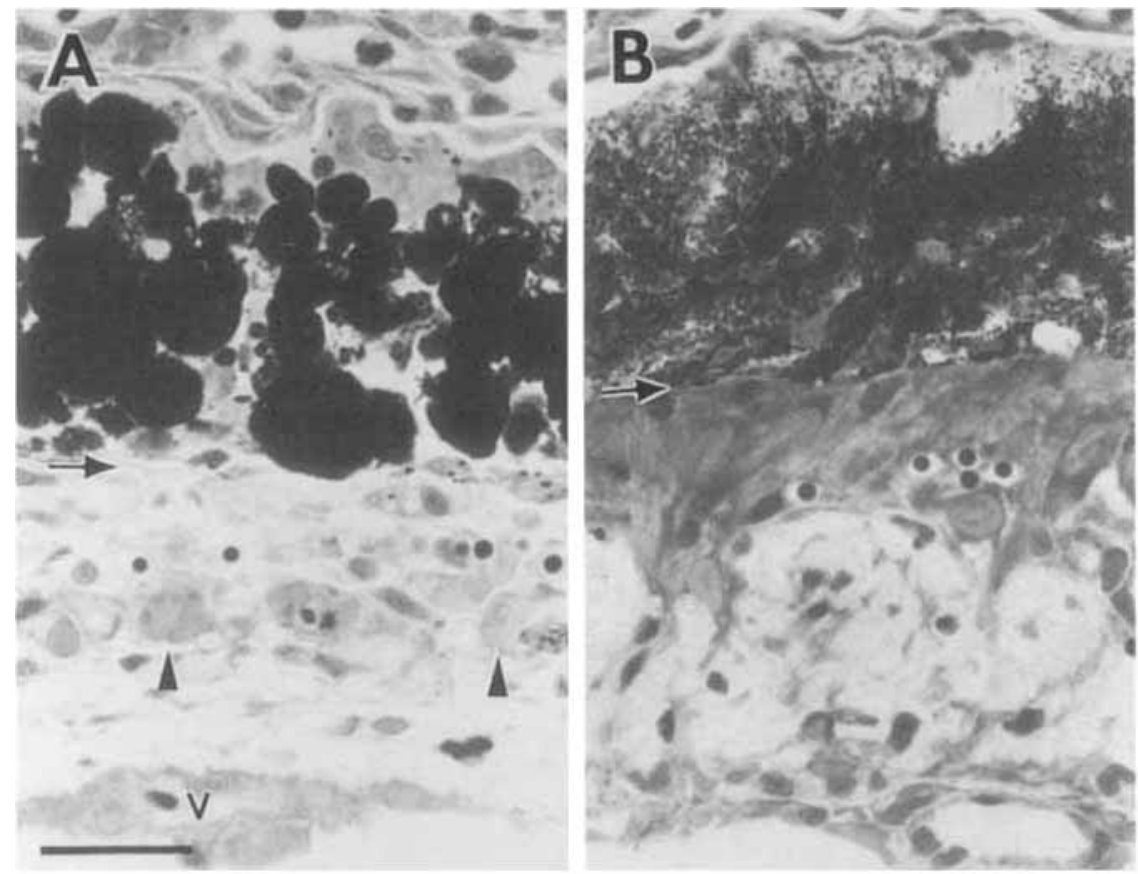

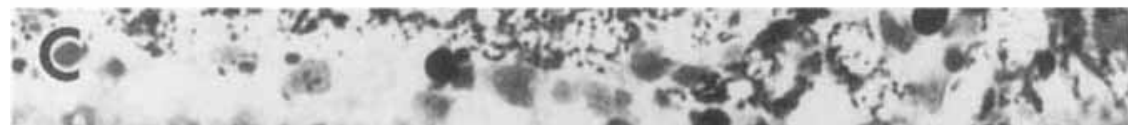

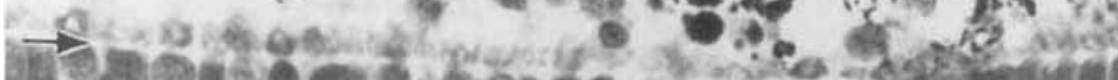

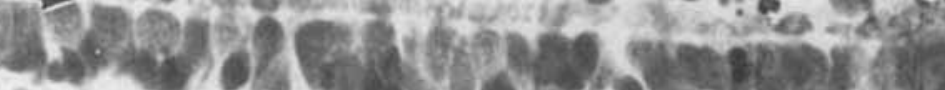

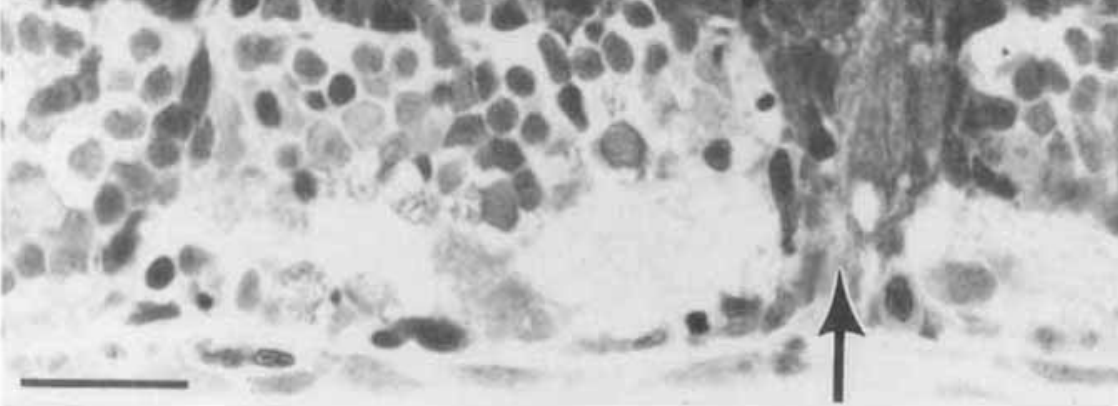

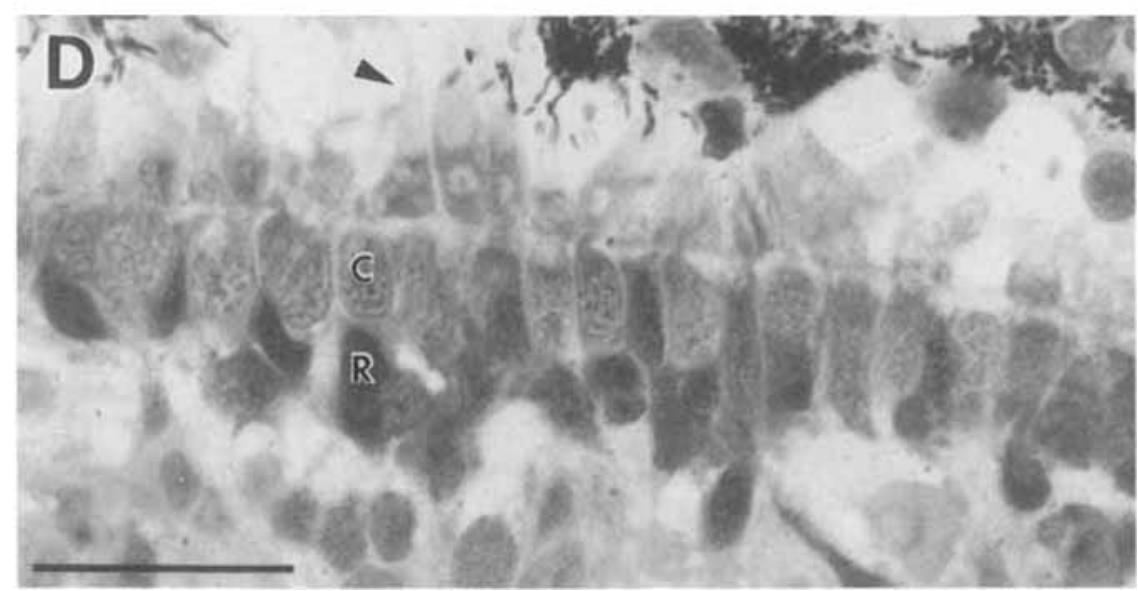


retinas from the same fish were also examined. The thickness of retinal layers was measured, and photoreceptor nuclei (rods and cones) were counted in 1 or 2 meridional sections (parallel to the dorsoventral axis) from each eye. Five camera lucida drawings were made from each section at a magnification of $1150 \times$ with an oil immersion objective. Each drawing covered a $95.7 \mu \mathrm{m}$ increment of retina, and the drawings were spaced at approximately equal intervals across the retina to provide representative samples of various regions. The contours of the retinal layers were traced, and the position of every rod and cone nucleus in the field was marked. For each fish, separate tallies were made for cone and rod densities in dorsal and ventral retina, since the degree of damage varied along this axis (see Results). The position of the optic disc was used to define the boundary between dorsal and ventral retina (Raymond, 1986). In meridional sections, the distance from retinal margin to optic disc is approximately $20 \%$ longer dorsally than ventrally (Raymond, 1986), so 3 of the 5 sampling regions fell in dorsal retina, and the remaining 2 were in ventral retina. In each sample, at least five intact cones were identified, and the lengths of their ellipsoids were measured. This measurement was useful in determining whether the cones had survived the toxin or were regenerating.

To further characterize retinal regeneration, in addition to these quantitative measures the same experimental retinas described in the preceding paragraph (excluding those at 2 weeks when regeneration was minimal) were scored qualitatively for surviving cones, surviving rods, regenerating cones, regenerating rods, regenerating neurons in inner retinal layers (ganglion cell and inner nuclear layers combined), and the presence of neurogenic foci (see Results). Five samples were scored in each retina. For each of the 6 cell types, a value of 1.0 was entered if present, 0.0 if absent, and 0.5 if present but sparse, or questionable. Regenerating and surviving cones were identified by morphological criteria (see Results). Regenerating neurons in the inner layers were identified by their patchy distribution and the periodic fusions between nuclear layers (see $\mathrm{Re}$ sults). For each of the 6 cell types, the scores were summed across the 5 sampling regions in each retina to yield a number between 0.0 and 5.0. Thus each retina was characterized by a list of 6 numbers between 0.0 and 5.0 . Because the data did not fit a normal distribution, nonparametric statistics were used to look for correlations among the six variables (Siegel, 1956).

To determine the relationship between retinal damage and mitotic activity, in a separate experiment fish were injected intraperitoneally with ${ }^{3} \mathrm{H}$-thymidine 3 weeks after ouabain was injected intraocularly. One week later their retinas (both experimental and control eyes) were processed for autoradiography. All sections were processed simultaneously. Three meridional sections were selected from each eye, and all labeled cells except those in the circumferential growth zone were counted. Only cells with five or more silver grains overlying the nucleus were included in the counts. The average number of labeled cells per section was determined for ventral and dorsal retina for each eye, and the percent difference between experimental and control eyes was calculated. To assess the degree of retinal damage, the thickness of the retina from inner to outer limiting membranes and the thickness of the outer nuclear layer alone were measured at 5 locations along the retina. For each sample in each experimental retina, these measurements were compared with an equivalent region of the control eye, and the mean percent difference in thickness of the outer nuclear layer and of the entire retina was calculated for each fish.

Fig. 2. Retinal regeneration following total destruction. (A) In this retina, 1 day after ouabain injection, the processes of the pigmented epithelial cells were rounded up, and photoreceptors were degenerated. Intact Müller cell nuclei (arrowheads) were seen in the region corresponding to the former inner nuclear layer, and the external limiting membrane was intact (arrow). Blood vessels (V) were seen along the vitreal surface. (B) In this retina, 2 days after ouabain injection, masses of basophilic, elongated proliferating cells were clustered beneath the external limiting membrane (arrow). (C) At 4 weeks after ouabain injection, focal nests of proliferating cells (large arrow) were interspersed with immature cone nuclei in the reconstituted outer nuclear layer just beneath the external limiting membrane (small arrow). Developing neurons in inner layers were also present. (D) A micrograph at higher magnification showing the developing outer nuclear layer from another retina at 4 weeks. Note the developing processes of the young cones (arrowhead). The darker, smaller nuclei beneath the single row of cones (C) are probably young rods $(R)$. Bars $=20 \mu \mathrm{m}$. (The bar in A also applies to B.) 

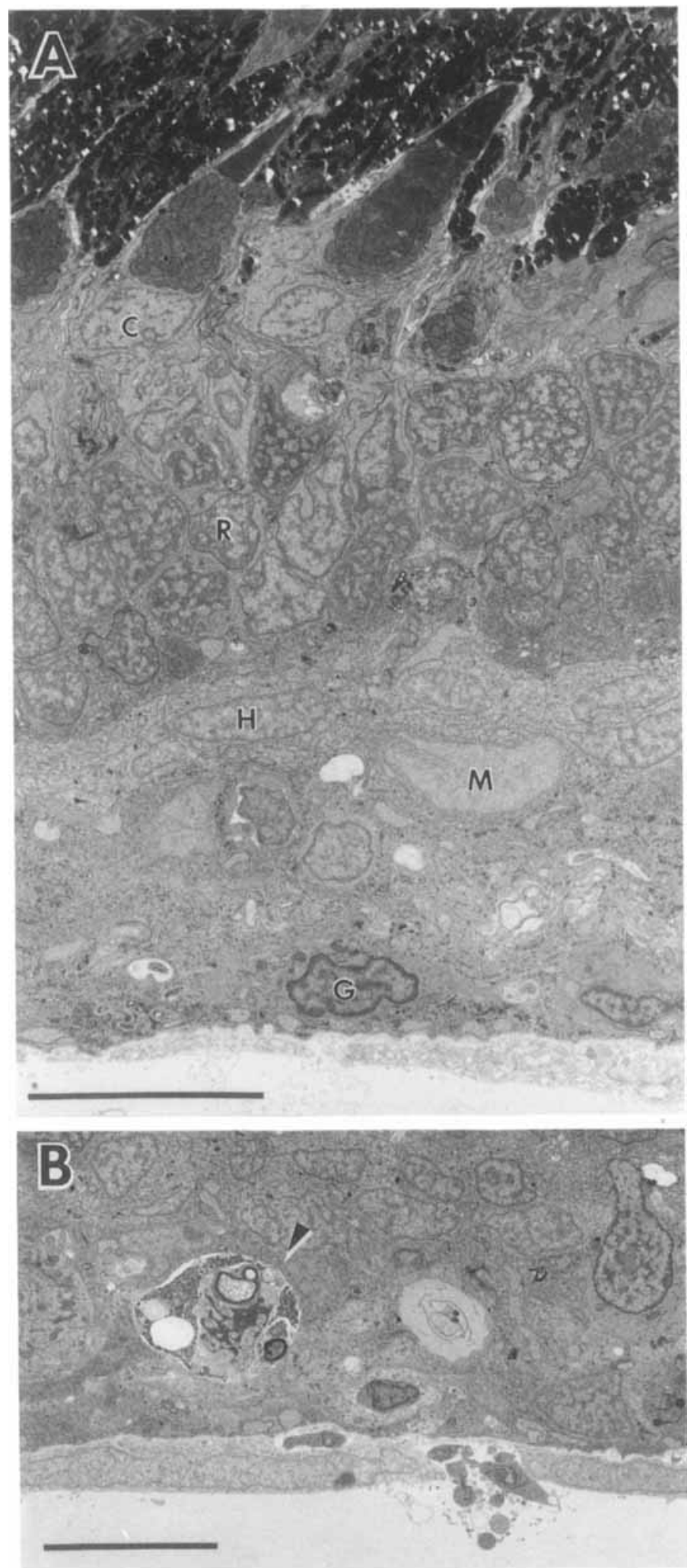


\section{RESULTS}

The results reported here are based on successful injections of ouabain into the right eye of 189 fish. On gross inspection, the lenses of the eyes injected with ouabain were often opaque, presumably due to a disturbance of ion transport mechanisms in the lens epithelium (Davson, 1980). In addition, the fish showed a "dorsal light reflex" (Walls, 1967). This reflex is triggered when there is an imbalance in the amount of visual input to the two eyes, as in monocular blinding. Such fish tilt with the blinded side upward, toward the brightest source of light, in an attempt to balance the neural output from the two eyes.

\section{Retinal Damage Produced by Ouabain}

We used a wide range of concentrations of ouabain in our initial experiments: $1.4 \mu M$ to $1.4 \mathrm{mM}$. In all cases, $1 \mu \mathrm{L}$ of the ouabain solution was injected into the right eye; the estimated intraocular concentrations ranged from 0.05 $\mu M$ to $50 \mu M$. (The range of estimated intraocular concentrations was larger than the range of concentrations injected because the eyes varied somewhat in size.) Table 1 indicates the general level of damage to neural retina in 72 fish examined 1 week or less after ouabain. Concentrations below $1 \mu M$ resulted in no apparent loss of retinal cells; between 1 and $7.5 \mu M$, neural retina was partially or completely destroyed. The full range of effects (no cell loss to complete loss of all retinal layers) was seen at concentrations between 1.0 and $2.5 \mu M$. Eyes with equivalent estimated intraocular concentrations within this range could show marked differences in amount of damage. This probably reflects inaccuracies in the estimation of intraocular ouabain concentrations due to errors in estimating ocular volume and/or uncertainties in the amount of ouabain injected. Kurz-Isler and Wolburg (1982) noted similar problems with reproducibility of ouabain lesions. Intraocular concentrations of approximately $50 \mu M$ were lethal within $24 \mathrm{~h}$ (Table 1 ). Concentrations between 7.5 and $50 \mu M$ were not investigated.

The remainder of this report deals with fish in which the estimated intraocular concentration of ouabain was 1.0-2.5 $\mu \mathrm{M}$. Under these conditions the neural retina degenerated, either partially or completely (Table 1 and Fig. 1). In all cases the left (control) retinas showed no evidence of retinal damage, whether injected with saline [Fig. 1(A)] or not. We conclude that neither mechanical trauma due to the incision, nor the presence of the needle, nor the injection of fluid were responsible for the retinal degeneration we observed. Furthermore, at ocular concentrations below $7.5 \mu M$, any ouabain that escaped from the injected eye into the systemic circulation was diluted below threshold for producing retinal damage in the contralateral eye.

The amount of retinal damage produced and the rate at which it progressed varied substantially, but, in general, with higher dosages degeneration was more rapid and more severe. Our observations confirm those of Maier and

Fig. 3. Electron micrographs showing degeneration of inner layers with sparing of photoreceptors. (A) In this retina, 2 weeks after ouabain, cones (C) and rods (R) were preserved. Horizontal cells (H), Müller cells (M), and glia $(G)$ could be found. (B) A macrophage (arrowhead) near the vitreal surface. This micrograph is from the same retina as in panel A. Bars $=10 \mu \mathrm{m}$. 
Wolburg (1979), except that the concentrations they found effective at producing retinal damage were approximately 2-10 times higher than ours. This may be due to the fact that the goldfish they used were larger $(7-12 \mathrm{~cm}$ body length) than ours $(3-4 \mathrm{~cm})$. Maier and Wolburg (1979) have described the sequence and approximate time course of degeneration, so we present only a brief summary of our observations.

As early as 1 day after injection of ouabain, pyknotic nuclei were found in the neural retina [Fig. 1(B)]. In the most severe cases, degeneration progressed very rapidly, and there were no recognizable retinal laminae by 1 day [Fig. 1(C)]. In less affected retinas, pyknotic nuclei were seen predominately in the inner retinal layers (ganglion cell layer and inner nuclear layer). The cell bodies of the pigmented retinal epithelium in general survived and remained in a single row [Fig. $1(\mathrm{C})$ ], although in retinas in which photoreceptors were destroyed, the processes of the pigmented epithelial cells eventually rounded up and disintegrated [Fig. 2(A)]. In most cases, the external limiting membrane was not compromised, and Müller cells survived, even when most or all retinal neurons were lost [Fig. 2(A)].

In some retinas inner retinal layers lost cells, but the outer nuclear layer (containing photoreceptor nuclei) remained intact, and the processes of photoreceptor cells and pigmented epithelial cells appeared undamaged [Fig. 1(D)]. Ventral retina tended to be more severely affected than dorsal, so that in some eyes the ventral retina was totally destroyed, whereas in dorsal retina the outer nuclear layer was spared.

In previous studies of ouabain-lesioned retinas, Wolburg (1976) and Maier and Wolburg (1979) found that Müller glia and horizontal cells were more resistent to ouabain toxicity than other retinal cells, and our data confirm their observations. In those retinas in which inner layers were destroyed, some cells persisted between the (intact) outer nuclear layer and the vitreal surface [Fig. 1(D)]. By electron microscopy these were identified as Müller glia and horizontal cells [Fig. 3(A)]. Müller glia were recognized by their pale, deeply clefted nuclei and the abundant glycogen in their cytoplasm (Raymond and Rivlin, 1987). Horizontal cells had distinctive flattened nuclei, pale cytoplasm, and abundant microtubules (Wolburg, 1976). Near the inner limiting membrane, glia [Fig. 3(A)], vascular elements [Fig. 2(A)], and macrophages [Fig. $3(B)]$ were also seen, and the latter were common in all damaged retinas, especially during the first month. The Müller cells and horizontal cells in partially damaged retinas probably represented cells that were not destroyed by the ouabain, since they were found consistently in partially damaged retinas at different intervals $(2,4,6$, and 10 weeks) after ouabain. We have not attempted to quantify these cells, so we do not know whether their numbers were increased or decreased compared with intact retinas.

\section{${ }^{3} H$-ouabain Binding Sites}

In the retina, $\mathrm{Na}^{+}, \mathrm{K}^{+}$-ATPase is found predominantly in the inner segments of photoreceptors and in the inner and outer plexiform layers (Stirling and Lee, 1980; Stahl and Baskin, 1984; McGrail and Sweadner, 1986). Since photoreceptors have abundant $\mathrm{Na}^{+}, \mathrm{K}^{+}$-ATPase, we wondered why they were less susceptible to toxic destruction by ouabain than were neurons in the inner 
layers. We suspected that the gradient of damage we observed was due to differential access of the drug to the various retinal layers. To determine how far the ouabain penetrated into the retina and where it was bound, we injected ${ }^{3} \mathrm{H}$-ouabain at concentrations equivalent to those used for the other experiments. These retinas were processed for freeze-dried autoradiography, a procedure which allows soluble or diffusible radioisotopes to be localized in tissues (Ernst and Mills, 1980). The highest density of autoradiographic grains following intraocular injection of ${ }^{3} \mathrm{H}$-ouabain was over the inner plexiform layer (Fig. 4), but labeling above background levels was seen throughout the retina. (Background was approximately 2 grains $/ 100 \mu \mathrm{m}^{2}$.) These results showed that

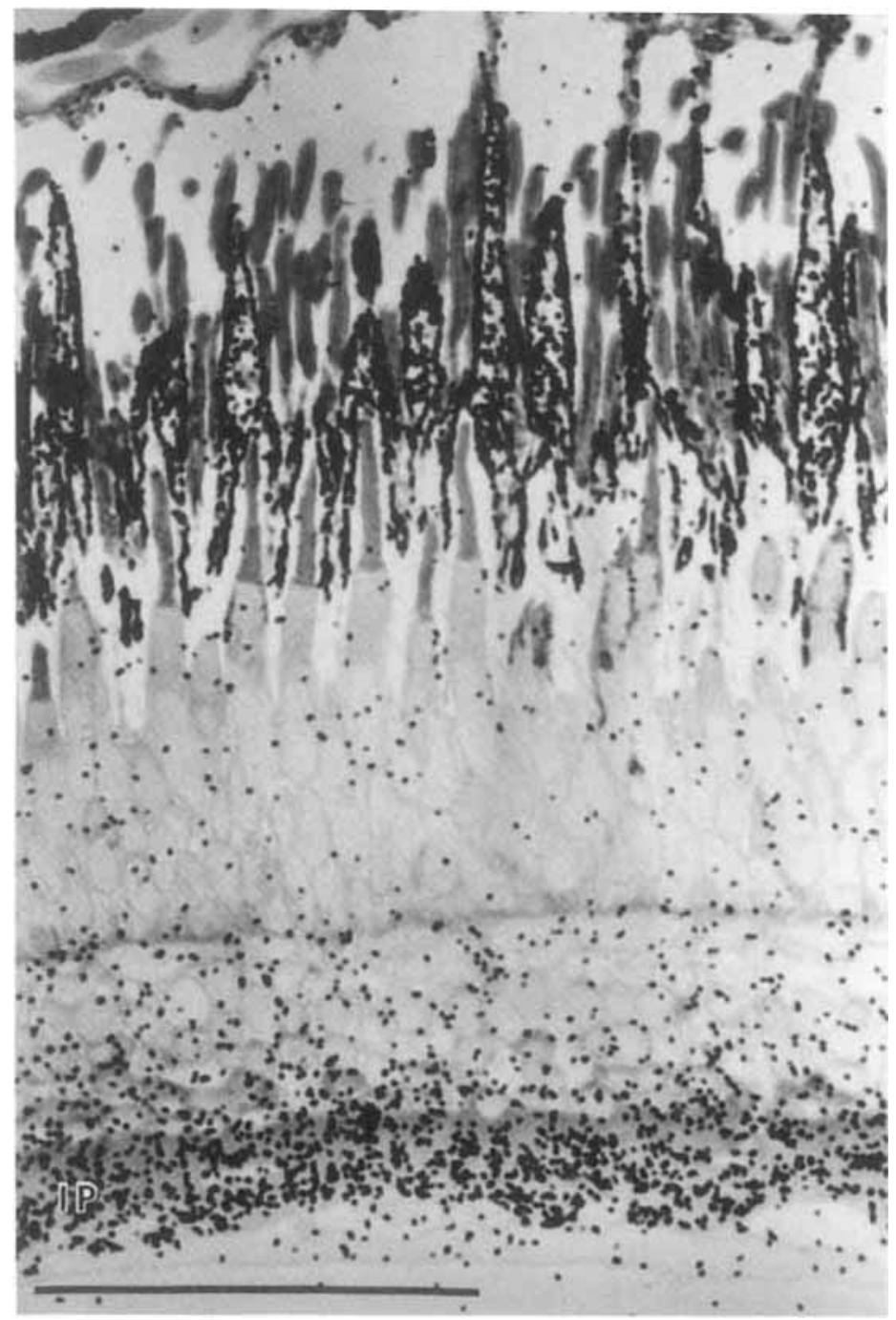

Fig. 4. Pattern of ${ }^{3} \mathrm{H}$-ouabain binding. Silver grains were most heavily concentrated over the inner plexiform layer (IP). Bar $=50 \mu \mathrm{m}$. 

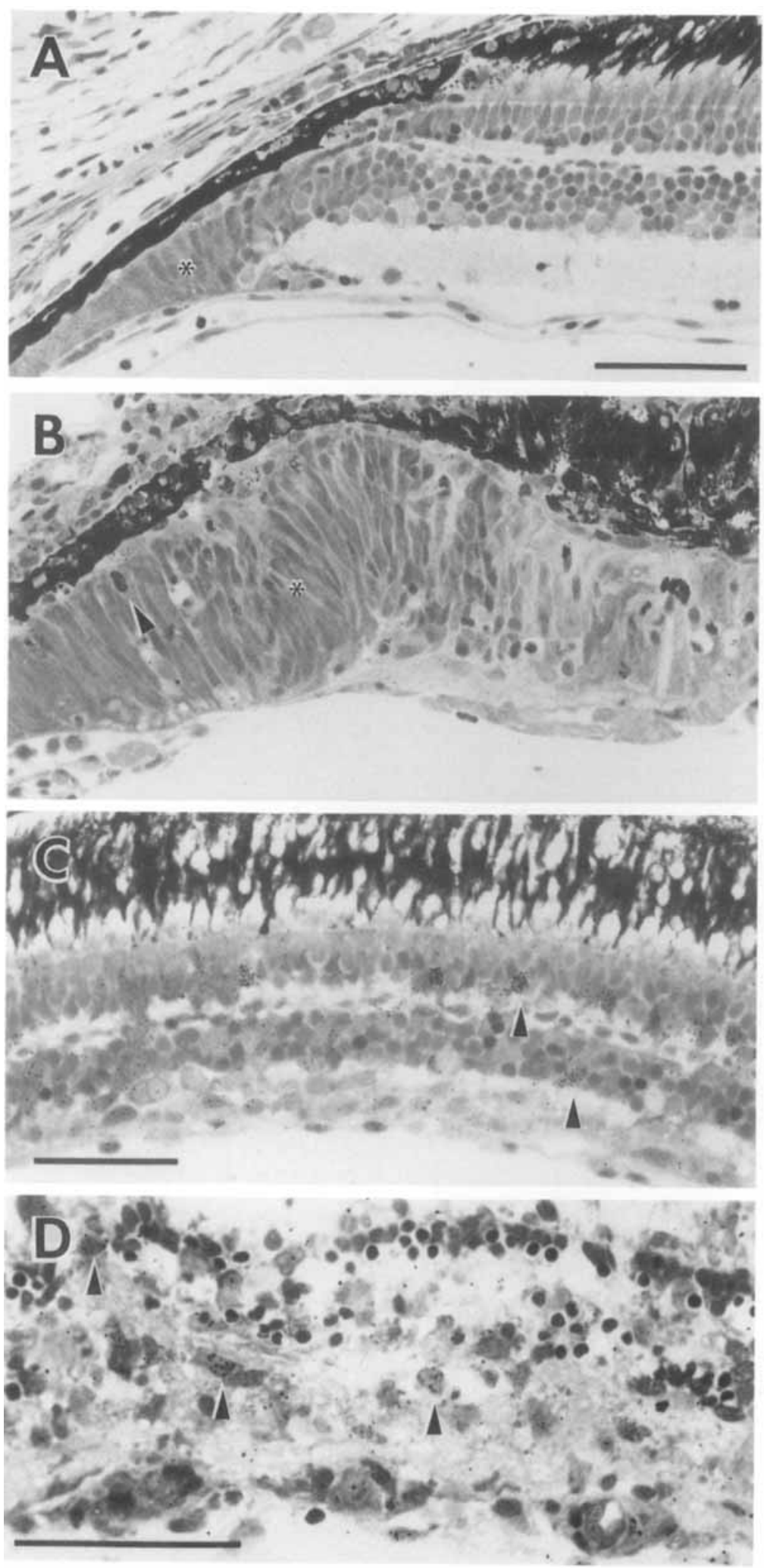
our suspicions were correct: ouabain-binding sites in inner retina had better access to the ligand than those in outer retina.

\section{Mitotic Stimulation Following Ouabain Injections}

In all ouabain-treated retinas, no matter how badly damaged, mitotic activity was enhanced in the circumferential germinal zone and in central retina (Maier and Wolburg, 1979; Fig. 5 in the present paper). Figure 5(A,B) compares the circumferential germinal zone in the control and experimental retinas, respectively, of a fish 1 week after ouabain injection. The germinal zone in the retina exposed to the toxin was greatly expanded, and the cells were actively dividing (Fig. 5B). Cell proliferation was also enhanced in central retina, especially in the outer nuclear layer. These dividing cells could be labeled with ${ }^{3} \mathrm{H}$-thymidine, as shown in Fig. 5(C,D). Labeled cells in the outer nuclear layer were probably rod precursors, since they were similar in appearance to those in intact retinas, although more abundant after ouabain treatment. Labeled cells were infrequently found in the inner nuclear layer of intact retinas in fish of this size but were typically seen in ouabain-treated retinas. Their identity is uncertain. They might be Müller cells that had been stimulated to divide, or they might belong to a reserve (or "resting") population of undifferentiated cells (see Discussion). They were seen in almost all experimental retinas, as early as 1 day after ouabain injection, even in retinas with no obvious cell loss or retinal damage. For this reason, we believe that the toxin itself may have had a direct mitogenic activity (see Discussion).

Other dividing cells that could be labeled with ${ }^{3} \mathrm{H}$-thymidine were located in the ganglion cell/optic fiber layer and were presumed to be glia or vascular elements. Both of these cell types are also found in the intact goldfish retina, where they can be labeled with ${ }^{3} \mathrm{H}$-thymidine (Johns, 1982), but again they were more abundant in the ouabain-treated retinas.

\section{Regeneration of Neural Retina Following Destruction by Ouabain}

By 1-2 weeks after ouabain injection, regeneration was evident in retinas that had undergone total or near total loss of retinal neurons. Focal sites containing nests of elongated cells with basophilic cytoplasm were scattered across the retina [Figs. $2(\mathrm{~B}, \mathrm{C})]$. These cells could be labeled with ${ }^{3} \mathrm{H}$-thymidine, indicating that they were mitotically active. These nests of proliferating cells resembled, in miniature, the circumferential germinal zone [Fig. 5(A,B)], although some were located in central regions far from the germinal zone even

Fig. 5. Stimulation of mitotic activity following ouabain injection. (A) The circumferential germinal zone (*) from a control eye, and (B) the circumferential germinal zone from the experimental eye of the same fish, 1 day after oubain injection. Note the mitotic figure on the experimental side (arrowhead). (C) This autoradiograph is from a fish injected intraocularly with ${ }^{3} \mathrm{H}$-thymidine, followed by ouabain injection a day later, and prepared after 1 week. Labeled cells (arrowheads) were seen in the outer and inner nuclear layers of this retina, in which cell loss was minimal. (D) This autoradiograph is from a preparation similar to the one in panel C, except that in this retina there was extensive cell loss. Round, dark pyknotic nuclei near the top of the panel represent the remnants of the outer nuclear layer, and there are three labeled nuclei (arrowheads). Bars $=50$ $\mu \mathrm{m}$. (The bar in A also applies to B.) 

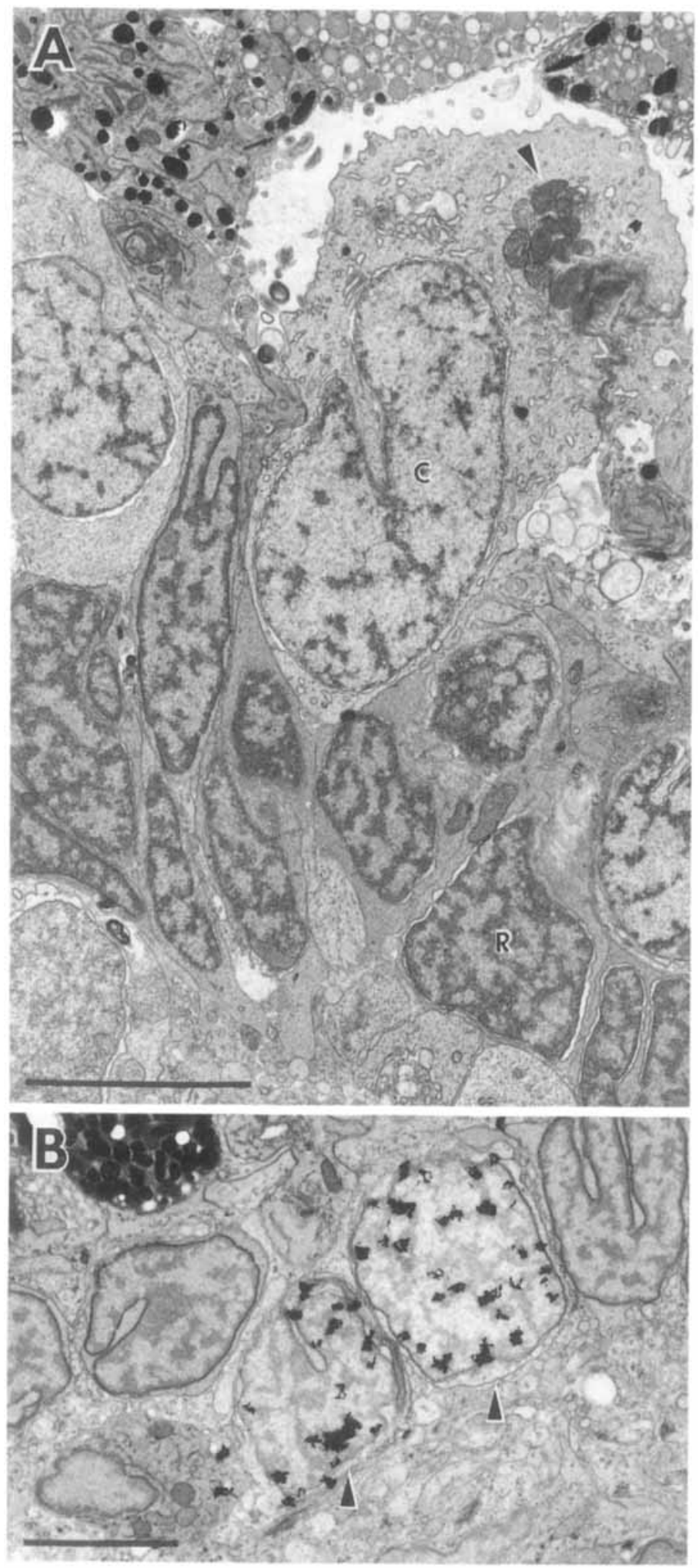
at the earliest times (2-3 days). Like the cells in the circumferential germinal zone, these nests of cells were directly apposed to the external limiting membrane. We call these collections of dividing cells "neurogenic foci," and we provide evidence later that the name is justified in that it describes their role in regeneration.

By 4 weeks after injection, patches of regenerated neurons could be seen flanking the neurogenic foci [Fig. 2(C,D)]. The outer nuclear layer at this stage consisted of a single row of regenerating cones. We identified these as immature cones, because they had the ultrastructural characteristics of developing cones in larval goldfish retinas (Raymond, 1985). Most obvious were their columnar-shaped, relatively electron-lucent nuclei and their incipient inner segments [club-shaped processes filled with mitochondria that protruded through the external limiting membrane; Fig. 6(A,B)]. Although immature cones were easily recognized, it was difficult to know whether cells in the inner layers had regenerated or survived. To show that cones and other retinal neurons had regenerated, ${ }^{3} \mathrm{H}$-thymidine was administered 3 or 4 weeks after ouabain injection, and 1 week later the eyes were processed for autoradiography. The cells labeled in these preparations had undergone their terminal mitotic division shortly after the ${ }^{3} \mathrm{H}$-thymidine was injected, and in the intervening week they had begun to differentiate. Labeled cells were found in all 3 retinal layers (Fig. 7). We can conclude that these labeled cells had been born shortly after the ${ }^{3} \mathrm{H}$-thymidine injection; i.e., they had regenerated. The history of unlabeled cells cannot be specified. They could have survived the ouabain or they could have regenerated but with a birthdate either before or after the pulse of ${ }^{3} \mathrm{H}$-thymidine.

Regeneration was always uneven, so that in a given retina some regions were further advanced than others. For example, in Fig. $7(\mathrm{~A})$ the two adjacent regions illustrated at higher magnification in Fig. $7(B, C)$ were at different stages of regeneration. In Fig. 7(B) labeled cells included immature cones and cells in the inner nuclear and ganglion cell layers. In Fig. 7(D) a labeled ganglion cell from another region of this retina is illustrated. In Fig. 7(C) only rod nuclei were labeled, and cones were more differentiated than in panel Fig. $7(B)$. One interpretation of these observations is that Fig. $7(B)$ represents an earlier stage in the regeneration process during which cones and cells in the inner layers were being produced. Fig. $7(\mathrm{C})$ would represent a later stage, when cones and inner layers were no longer accumulating, and rods were finally being added. We suggest this scenario because it represents the temporal sequence of cell birthdates followed during development in embryonic and larval goldfish (Sharma and Ungar, 1980; Johns, 1982). Furthermore, a systematic examination of photoreceptor cell numbers at various times during regeneration supported the inference that cones were born first and rods were added later, just as during normal development. This analysis is presented next.

Fig. 6. Electron micrographs illustrating regenerating retinal neurons. (A) At 4 weeks after ouabain injection, regenerating immature cones (C) had developing inner segments that contained collections of mitochondria (arrowhead). Vitread to the cones were developing rod nuclei (R). (B) In this retina, labeled with ${ }^{3} \mathrm{H}$-thymidine at 2 weeks after ouabain injection and processed for autoradiography 1 week later, young cone nuclei were labeled (arrowheads). Bars $=5 \mu \mathrm{m}$. 

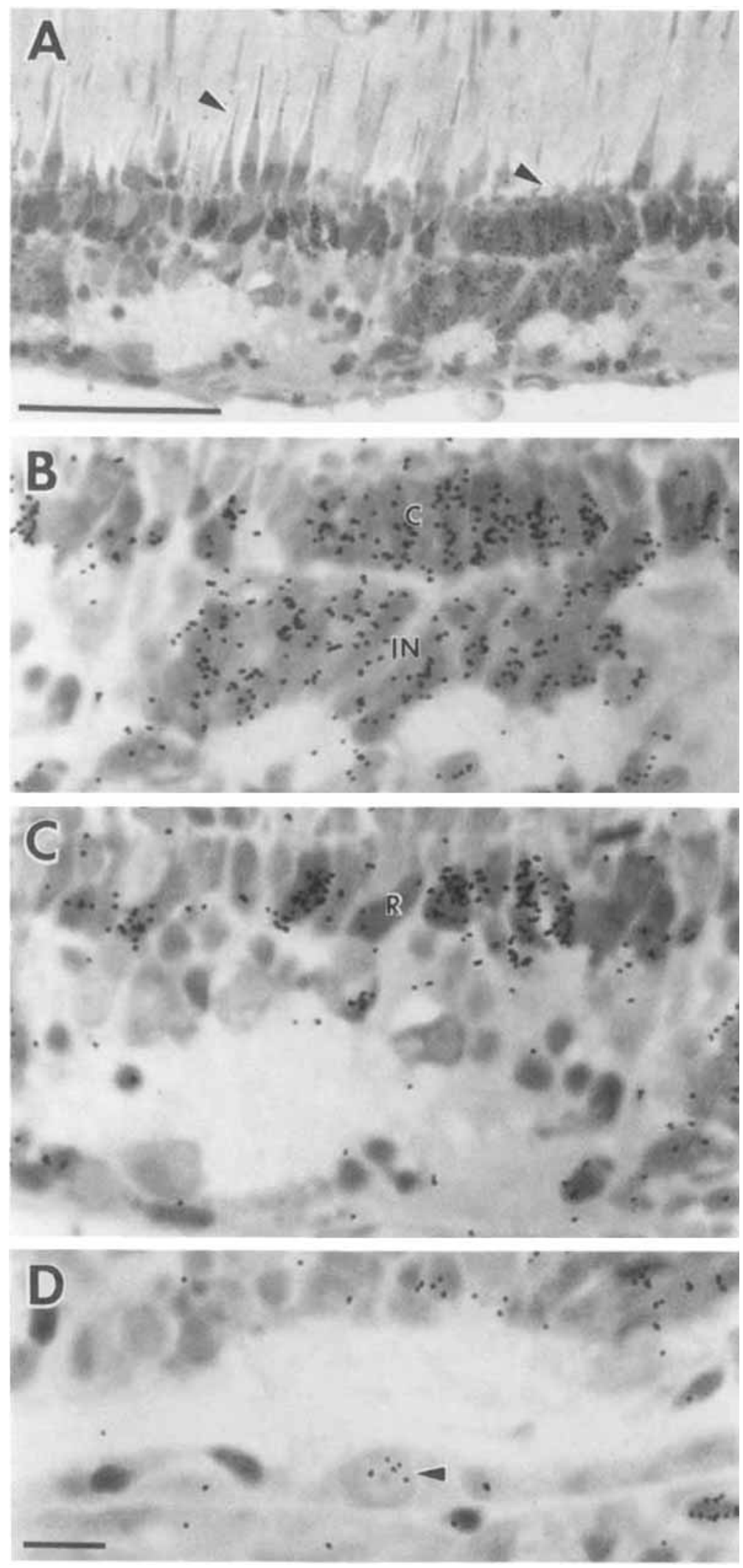
To follow the time course of photoreceptor regeneration, we first had to develop a method to distinguish those that were regenerating from those that might have survived the toxin. The best way would have been to apply ${ }^{3} \mathrm{H}$ thymidine continuously in order to label all newly produced cells, but this was impractical for a number of reasons. Instead we used morphological criteria that were developed in a previous study of photoreceptor differentiation in larval goldfish (Raymond, 1985). In that study immature and mature rods and cones were distinguished with a selective marker, ${ }^{3} \mathrm{H}$-fucose, which is incorporated into cone but not rod outer segment membranes in goldfish. The morphological features and the dimensions of outer segments, ellipsoids, and nuclei of photoreceptors were charted in fish from hatching to 4 years in age. Mature cones could be distinguished from immature cones by two primary criteria: length of the ellipsoids and position of the nuclei. Ellipsoids grew slowly but continuously throughout the 4 -year period. Cone nuclei were initially ovoid and were located on the vitread side of the external limiting membrane, but over the next month they penetrated through it, coming to rest midway across. Mature cone nuclei were peanut-shaped with a constriction at the level of the limiting membrane. (In goldfish there are several morphologically distinct classes of cones, and this description of nuclear changes applies to double cones and long single cones; nuclei of short single cones remained on the vitread side.) The same sequence of maturation was observed in regenerating cones in the present study. Using these criteria cones were designated as survivors or regenerates in 32 fish examined at 2-10 weeks after ouabain injection. For each retina the mean ellipsoid length of double cones and long single cones, which are nearly identical in size (Raymond, 1985), is given in Table 2 . We routinely excluded short single cones from these measurements because their ellipsoids are about $2 \mu \mathrm{m}$ shorter than the others (Raymond, 1985). In ouabain-damaged retinas, cones with short ellipsoids and ovoid nuclei were designated as regenerates, and those with longer ellipsoids and constricted nuclei were classed as survivors (Table 2). At 6 weeks or longer after ouabain injection, ellipsoids of surviving cones were indistinguishable in length (9-10 $\mu \mathrm{m}$ ) from those in intact retinas (Raymond, 1985), but at 2 and 4 weeks ellipsoids of cones that appeared to be survivors based on nuclear morphology were shortened by about $1.5-2.5 \mu \mathrm{m}$. This probably represents reversible damage to the cone ellipsoid caused by the toxin. At 2 weeks, 1 of the 3 retinas examined in this experiment had no loss of cones [see Fig. 8(A)], and the ellipsoids in this case were normal in length (Table 2). As the regenerating cones matured, it eventually became difficult to decide whether they were indeed regenerating or had survived. This occurred in some cases by $8-10$ weeks (Table 2).

Fig. 7. Regenerated neurons labeled with ${ }^{3} \mathbf{H}$-thymidine. These autoradiographs are from a fish injected with ${ }^{3} \mathrm{H}$-thymidine 3 weeks after ouabain. The retina was processed for autoradiography 1 week later. (A) In this low magnification view, note the patchy distribution of regenerated neurons and the cones (arrowheads) at various states of maturation. Two adjacent regions in this field are shown at higher magnification in panels $B$ and $C$. (B) Labeled cells in this region included immature cones (C) and cells in the incipient inner nuclear layer (IN). (C) Labeled cells in this region were predominantly rod nuclei $(R)$ located vitread to the row of developing cones. (D) $A$ labeled ganglion cell (arrowhead) from another region of the same retina. Bars: A, $50 \mu \mathrm{m} ; \mathrm{D}, 10 \mu \mathrm{m}$ (also applies to $\mathrm{C}$ and $\mathrm{B}$ ). 
TABLE 2

Length of Ellipsoids as an Index of Surviving/Regenerating Cones

\begin{tabular}{|c|c|c|c|c|c|}
\hline & \multicolumn{5}{|c|}{ Weeks after Ouabain } \\
\hline & 2 & 4 & 6 & 8 & 10 \\
\hline Surviving Cones & $\begin{array}{l}9.3(0.6)^{a} \\
7.2(0.4)^{b} \\
6.9(0.6)^{b}\end{array}$ & $\begin{array}{l}7.6(1.0) \\
7.6(0.4)\end{array}$ & $\begin{array}{r}10.4(0.3) \\
9.4(0.7) \\
7.6(1.5)\end{array}$ & $\begin{array}{l}9.3(0.3) \\
8.5(0.6)\end{array}$ & $\begin{array}{r}10.9(0.6) \\
9.1(0.6)\end{array}$ \\
\hline $\begin{array}{l}\text { Surviving and/or } \\
\text { Regenerating }\end{array}$ & & $\begin{array}{l}7.8(0.7) / \\
4.0(0.3)^{d}\end{array}$ & $\begin{array}{l}7.6(0.7) / \\
5.7(1.2)^{d}\end{array}$ & $\begin{array}{l}8.1(0.6)^{c} \\
8.1(0.3)^{c}\end{array}$ & $\begin{array}{l}8.1(1.2)^{\mathrm{c}} \\
7.8(0.9)^{\mathrm{c}} \\
7.2(1.0)^{\mathrm{c}}\end{array}$ \\
\hline Regenerating Cones & & $\begin{array}{l}3.5(1.0) \\
0\end{array}$ & $\begin{array}{l}6.8(0.6) \\
6.0(0.3) \\
5.4(0.4)\end{array}$ & $\begin{array}{l}6.8(0.3) \\
6.0(0.6) \\
5.6(0.6)\end{array}$ & $\begin{array}{l}6.5(0.4) \\
6.2(0.4)\end{array}$ \\
\hline
\end{tabular}

${ }^{a}$ Mean (standard deviation) length of cone ellipsoids in micrometers. With 2 exceptions, the $n$ was 15 ( 5 cones, double cones or long singles, were measured in each of three $100 \mu \mathrm{m}$ samples from dorsal retina). Each entry is one retina. 'Three additional fish in the 2-week group had no surviving cones, and none had been regenerated, so no values appear on this table. One fish in the 4-week group had regenerating cone nuclei, but ellipsoids had not yet appeared, so the entry in the table is zero.

${ }^{b}$ In these 2 retinas there were $\leq 10$ cones per $100 \mu \mathrm{m}$.

${ }^{c}$ Regenerating and surviving cones could not be separately identified.

${ }^{d}$ Two distinct populations of cones (surviving and regenerating) could be recognized based on morphological criteria (see text).

Regenerating rods were identified by their outer segments, which were similar to developing rod outer segments in the larval retina (Raymond, 1985). Mature rod outer segments are about $1.5 \mu \mathrm{m}$ in width and $25 \mu \mathrm{m}$ in length, and they are typically straight and aligned perpendicular to the retinal laminae (Raymond, 1985). Developing rod outer segments are very distinctive in that they are shorter and wider (up to $2.5 \mu \mathrm{m}$ in width), and they are initially bent tangentially. However, within a few days the nascent outer segment elongates and straightens and can no longer be distinguished from its older siblings. Unlike cones, nuclear morphology of rods does not change with maturation (Raymond, 1985). Regenerating rods were similar in form to immature rods, although we did not attempt to measure them systematically.

With these criteria established, we counted regenerating and surviving rod and cone nuclei in 32 retinas at $2-10$ weeks after ouabain. Nuclear counts (number per $100 \mu \mathrm{m}$ length of retina) from dorsal retina are plotted in Fig. 8 (cones in A and rods in B). Counts from ventral retina (not illustrated) showed similar trends. The mean values for the left (control) eyes are indicated by the horizontal dashed lines, and the shaded areas denote one standard deviation above and below the mean. Cone ellipsoid measurements on these same retinas appear in Table 2. Some retinas had only regenerating photoreceptors, some had only survivors, and some had both, and in Fig. 8(A), these three conditions are represented by different symbols. When surviving and regenerating cones were present in the same retina, both were included in the nuclear counts. At early times (4-6 weeks) the linear density of regenerating cones was higher than the normal cone density [Fig. 8(A)], just as the density of immature cones in the larval retina is greater than in mature retinas (Johns, 
A

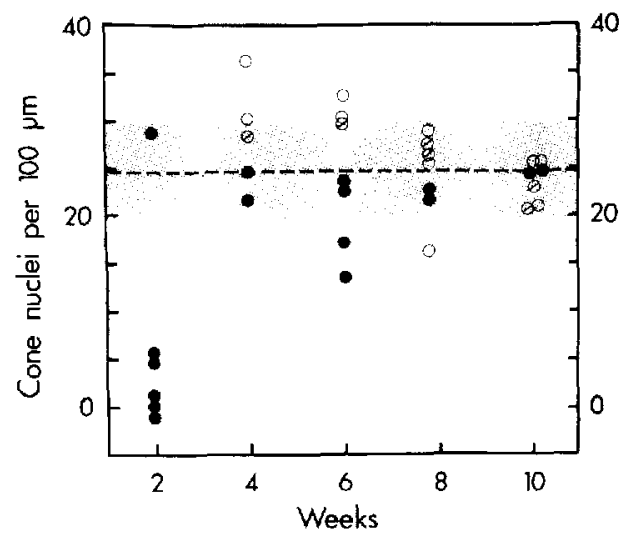

B

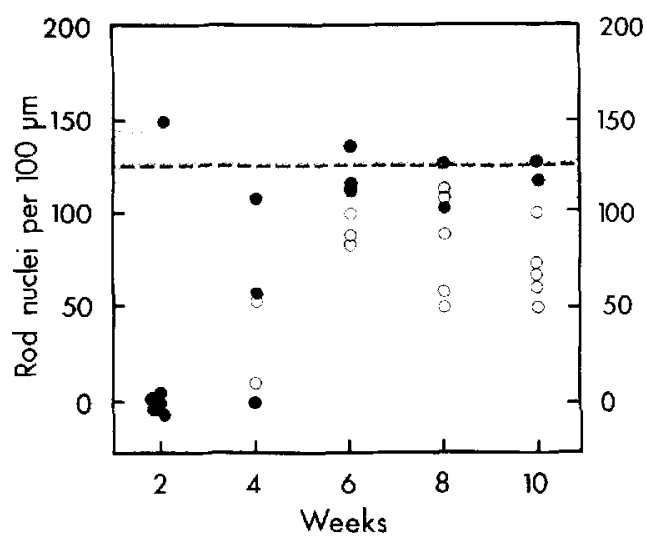

Fig. 8. Photoreceptor density in regenerating retinas. The linear densities (number per $100 \mu \mathrm{m}$ length of retina) of cone (A) and $\operatorname{rod}(\mathrm{B})$ nuclei are given as a function of time in weeks following injection of ouabain. Each point represents one retina; the symbols reflect whether the photoreceptors in that retina had survived (solid circles), were regenerated (open circles), or included a mixed population of survivors and regenerates (circle with oblique line). The horizontal dashed lines represent the mean densities in control eyes, and the stipled regions delineate plus and minus one standard deviation. All counts were made in dorsal retina.

1982). At this stage in the regenerative process, however, cones were distributed in patches, not uniformly across the retina [Fig. 7(A)]. By 10 weeks, the density of regenerating cones was nearly homogeneous across the retina and was indistinguishable from normal values [Fig. 8(A)]. In Fig. 8(B) density of 

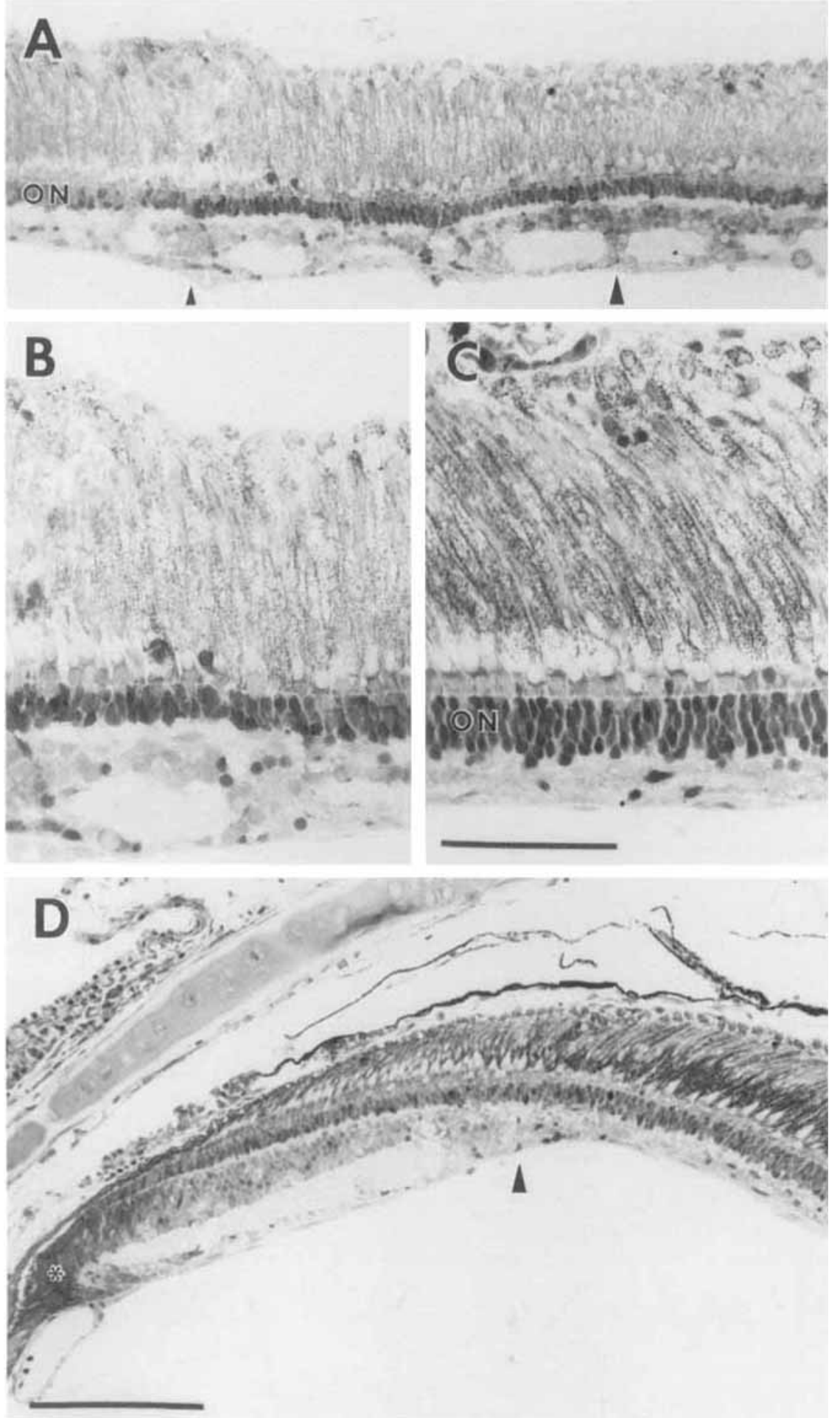
rod nuclei is plotted for the same 32 retinas. A solid symbol indicates that all rod outer segments in that retina were mature; an open symbol indicates that a substantial number of rod outer segments were immature, i.e., regenerating. In contrast to cones, the density of regenerating rods was consistently lower in injected eyes, and normal values were not yet reached by 10 weeks [Fig. 8(B)]. This difference in the pattern of rod and cone genesis reflects both a different time course and a different mode of production of these two cell types during regeneration as in development (Johns, 1982; Raymond, 1985; Raymond and Rivlin, 1987). That is, cones at a given locus on the retina are generated simultaneously, in a single layer, and they all slowly differentiate together. Rods are generated later, in a scattered and asynchronous fashion, and they mature rapidly but accumulate gradually.

\section{Source of the Regenerated Cells}

As mentioned already, regeneration did not occur synchronously throughout the retina. Instead, there were patches of well organized and less well organized areas [Figs. 9(A,B)]. The longest intervals we examined were 4 and 6 months ( 4 fish), and even then areas of disorganization persisted. The retina immediately adjacent to the circumferential germinal zone always looked completely normal [Fig. 9(D)], but this probably represented an increment of new retina that had been added as part of the normal process of growth (see Discussion).

When neurogenic foci were first evident, they were distributed across the retina. Figure 10 shows that at $4-10$ weeks after ouabain injection (which encompasses the period of most vigorous retinal regeneration), those retinas that contained abundant surviving rods [Fig. 10(A)] and surviving cones [Fig. $10(B)]$ had few neurogenic foci. In contrast, retinas that contained regenerating cones [Fig. 10(C)], regenerating rods (not illustrated; see legend to Fig. 10), or regenerating inner layers [Fig. 10(D)] tended to have abundant neurogenic foci. The strength of these correlations was tested using a nonparametric statistic (Spearman Rank Correlation; Siegel, 1956; pp. 202-213), and the values of the correlation coefficients are given in the legend to Fig. 10. These correlations were all highly significant. We conclude that the presence of neurogenic foci in the retina was correlated with regenerating neurons and negatively correlated with surviving neurons.

Fig. 9. Retinal cytoarchitecture months after ouabain injection. (A and B) In this retina, at 10 weeks after injection, the outer nuclear layer $(O N)$ had been reconstituted across the entire retina and appeared normal, except that the density of rod nuclei was still somewhat low. The inner layers were not as well organized, and there were periodic fusions between inner layers (arrowheads). Occasional fusions between inner and outer nuclear layers were also present. Panel B is a higher magnification view of part of the field in panel A. (C and D) In this retina, also at 10 weeks, there was no regeneration of inner layers, and the outer nuclear layer remained intact. This is best seen in panel $\mathrm{C}$, which is from central retina. (Note the increased density of surviving rod nuclei in this retina compared with the regenerated retina shown in panel B.) In panel D the margin of the same retina is shown. The arrowhead points to a sharp transition between unregenerated retina to the right (centrad) and retina which appears to be organized normally and was presumably added as a result of ongoing cell proliferation in the circumferential germinal zone (*) during the 10 week interval. Bars: C, $50 \mu \mathrm{m}$ (also applies to B); D, $100 \mu \mathrm{m}$ (also applies to A). 

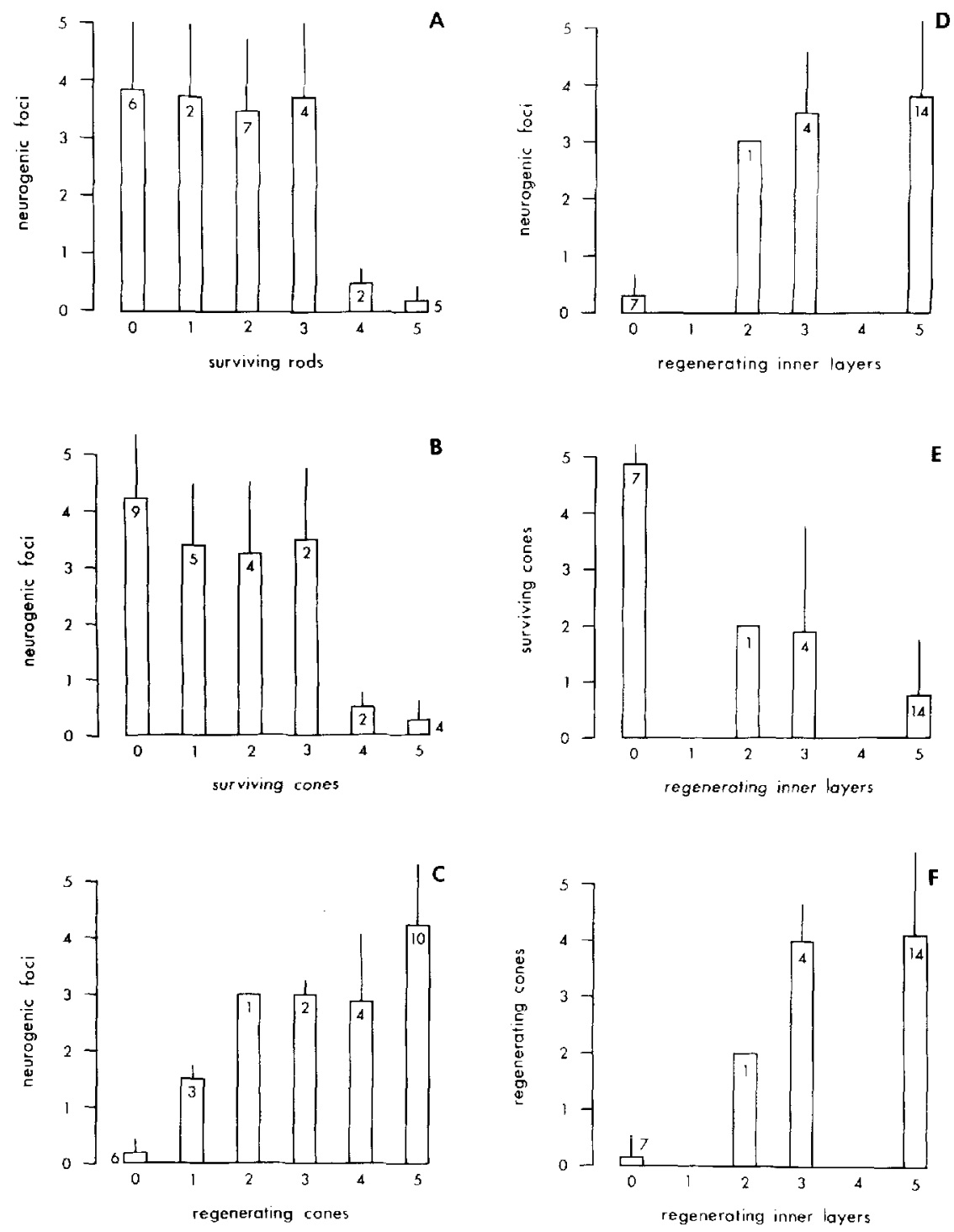

Fig. 10. Histograms illustrating pairwise comparisons of several parameters (cell types) associated with regeneration or sparing of cells following ouabain injections. For each cell type, each retina was assigned a value ranging from 0 to 5 (see Materials and Methods). The larger the number, the more frequent the occurrence of that cell type. The bars indicate the means for retinas in each category on the abscissa; the error bars are one standard deviation. The numbers within (or beside) each bar indicate the number of retinas in each category. A total of 26 retinas were included, all between 4 and 10 weeks after ouabain injection. The values of rho (the Spearman correlation coefficient) and the significance levels are as follows: (A) $-0.627, p<0.01$; (B) $-0.725, p$ $<0.001$; (C) 0.767, $p<0.001$; (D) 0.714, $p<0.001$; (E) $-0.741, p<0.001$; (F) $0.764, p$ $<0.001$. Other correlations not illustrated had the following values: neurogenic foci and regenerating rods, $0.600, p<0.01$; surviving rods and regenerating inner layers, -0.838 , $p<0.001$, regenerating rods and regenerating inner layers, $0.807, p<0.001$ ). 
We next addressed the question: Which cells in the intact retina gave rise to neurogenic foci? If they were derived from cells in the circumferential germinal zone that migrated inward to colonize the damaged retina, then they ought to have appeared first at the periphery and only later in central regions. We could not detect such a gradient, however. Regenerating loci were seen everywhere, including central retina, even at early times. This distribution is similar to that of rod precursors, which are scattered across the retina in normal fish (Johns and Fernald, 1981; Johns, 1982).

In order to determine whether rod precursors could provide a source of germinal cells for the regenerating retina, it was first necessary to show that they were not destroyed by the ouabain. It was easy to show that the mitotic neuroepithelial cells in the circumferential germinal zone always survived, even when the neural retina was completely destroyed [Fig. 5(B)], since the germinal zone is a discrete annular strip of tightly packed cells with a unique histological appearance. It is not easy to recognize rod precursors in normal histological preparations, however, since their nuclei are similar in size and staining density to mature rods that surround them. The most reliable way to recognize them is to label them with ${ }^{3} \mathrm{H}$-thymidine (Johns, 1982; Raymond and Rivlin, 1987). We therefore did the following experiment. Twelve fish were given multiple injections of ${ }^{3} \mathrm{H}$-thymidine within a $24-\mathrm{h}$ period to label a large fraction of the rod precursor population (see Materials and Methods). The following day they were injected intraocularly with ouabain, and 1,3 , or 7 days later the eyes were processed for autoradiography. In all 12 retinas, cells in the circumferential germinal zone were lightly labeled, indicative of repeated cell division. In those cases in which the outer nuclear layer remained partially or wholly intact (8/12), isolated cells in the outer nuclear layer and clusters in the inner nuclear layer were lightly labeled [Fig. 5(C)]. In cases sustaining nearly complete loss of retinal layers (2/12), scattered lightly labeled cells were also present [Fig. 5(D)]. Some of these cells had the cytological features (size, shape, and basophilic cytoplasm) of rod precursors. In all damaged retinas, rare but very heavily labeled cells were found, usually in the inner half (not illustrated). The high density of labeling over these cells indicates that they probably had divided only once after they incorporated the label, in contrast to rod precursors and cells in the germinal zone which had divided repeatedly. We do not know what these heavily labeled cells were, but we suspect that they were phagocytes. In the remaining two retinas, there was no obvious cell loss in any layer, but lightly labeled rod precursors and clusters in the inner nuclear layer were observed (not illustrated). We conclude that rod precursors survived in ouabain-damaged retinas.

\section{Failure of Regeneration in Retinas Sustaining Only Partial Damage}

Not all damaged retinas regenerated. Retinal regeneration occurred only when the lesion extended into the outer nuclear layer and destroyed most or all of the photoreceptors. Examples of retinas in which regeneration failed are illustrated in Figs. 9(C) and 11. In these cases, photoreceptors (both rods and cones) were intact, with well-developed inner and outer segments (Fig. 11). The axon terminals had synaptic ribbons and vesicles and a few invaginating postsynaptic processes (inset to Fig. 11), which probably belonged to the oc- 


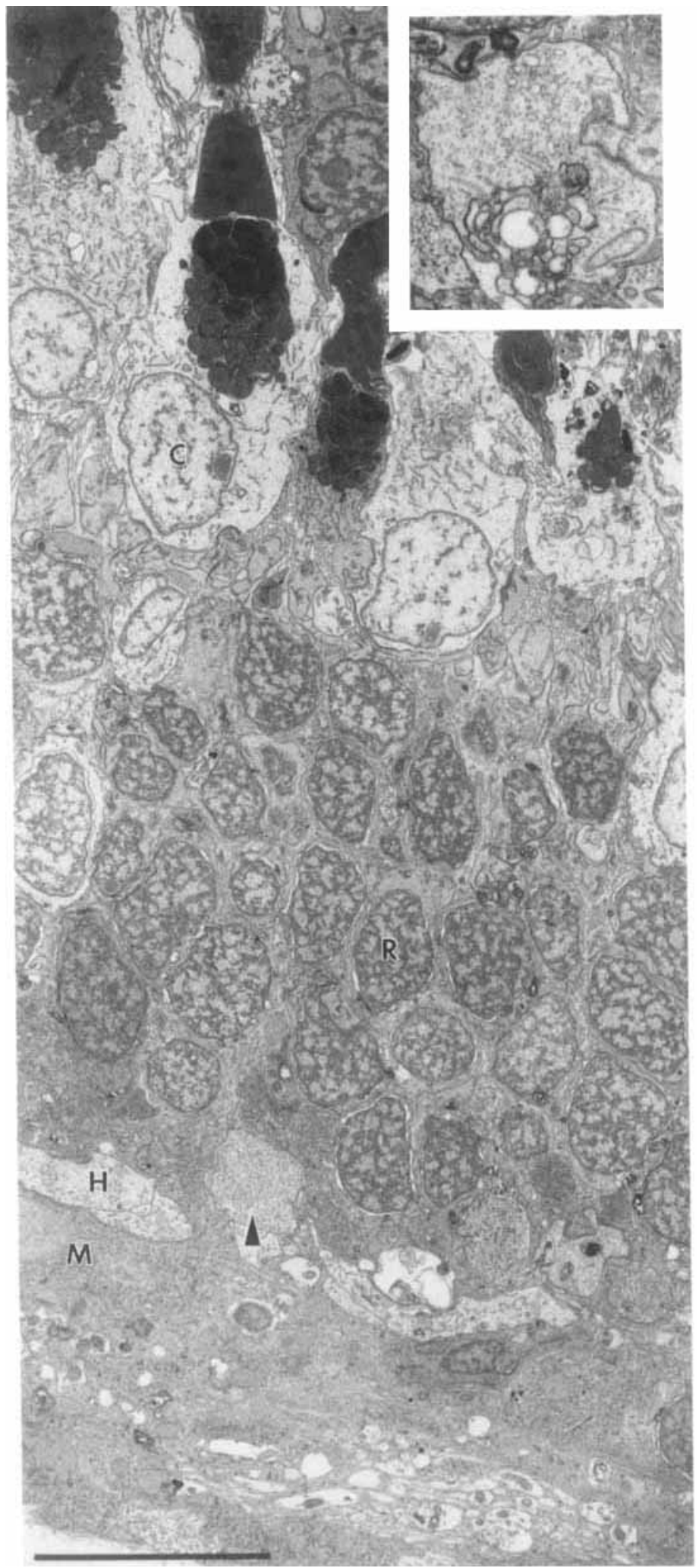


casional horizontal cells that remained. Müller cells were also present, as were glia and vascular cells near the vitread surface. Remnants of what once was the inner plexiform layer were seen in some regions, but the cellular origin of these neuronal processes is not known.

Further evidence that regeneration of inner layers did not take place unless photoreceptors were lost is given in Fig. $10(\mathrm{E}, \mathrm{F})$. The presence of surviving cones was negatively correlated with regeneration of inner layers [Fig. 10(E)]. Surviving rods showed the same relationship (not illustrated, see legend to Fig. 10). In contrast, regenerating cones were positively correlated with regenerating inner layers [Fig. 10(F)] and similarly for regenerating rods (not illustrated, see legend to Fig. 10).

The suggestion that regeneration occurred only when photoreceptors were destroyed was also corroborated when we compared the amount of ${ }^{3} \mathrm{H}$-thymidine labeling in retinas that had variable loss of cells in the outer nuclear layer. For this purpose, 7 fish were injected intraocularly with ouabain and 3 weeks later were given 3 intraperitoneal injections of ${ }^{3} \mathrm{H}$-thymidine spaced over a 24-h interval. One week later their retinas, both left and right, were processed for autoradiography. We counted thymidine-labeled cells, and we measured the thickness of neural retina and the outer nuclear layer. The width of the outer nuclear layer provides an index of photoreceptor number, especially number of rods, whose nuclei are entirely confined to this layer (LaVail et al., 1987; Raymond, 1985). Figure 12 shows that in all 7 fish, the damaged retina was reduced in overall thickness by approximately the same amount: on average, $54.6 \%$. This was accounted for by loss of the inner layers, which occurred in all seven cases. Stimulation of labeling in the experimental eye varied over an order of magnitude, from 300 to $3310 \%$, and was directly correlated with loss in thickness of the outer nuclear layer [Fig. 12(B), linear correlation coefficient, $r^{2}=0.917 ; p<0.01$ ]. We conclude that after ouabain injection, cell proliferation was stimulated in proportion to the amount of cell loss in the outer nuclear layer.

\section{DISCUSSION}

The most striking, and most surprising, result of this study was that neural retina in juvenile goldfish regenerated following a lesion which destroyed neurons in all cellular laminae but failed to regenerate when only the two innermost laminae (inner nuclear and ganglion cell layers) were disrupted. This result at first seems paradoxical: the more severely damaged retinas recovered better than the less affected ones. The paradox could be resolved if the source of stem cells for the regenerated retina were in the outer nuclear

\footnotetext{
Fig. 11. Electron micrograph of a retina that did not regenerate. In this retina, 10 weeks after ouabain injection, the photoreceptor layer contained a normal complement of rods (R) and cones (C). There had been no regeneration of inner retinal layers, which consisted primarily of the cell bodies and processes from horizontal $(\mathrm{H})$ and Müller $(\mathrm{M})$ cells that presumably survived the ouabain injection. Most axon terminals of photoreceptors (arrowhead) contained few postsynaptic invaginating processes, although synaptic ribbons and synaptic vesicles were present. Only rarely were cone terminals found with as many invaginating processes as the one in the inset. Bar $=10 \mu \mathrm{m}$.
} 

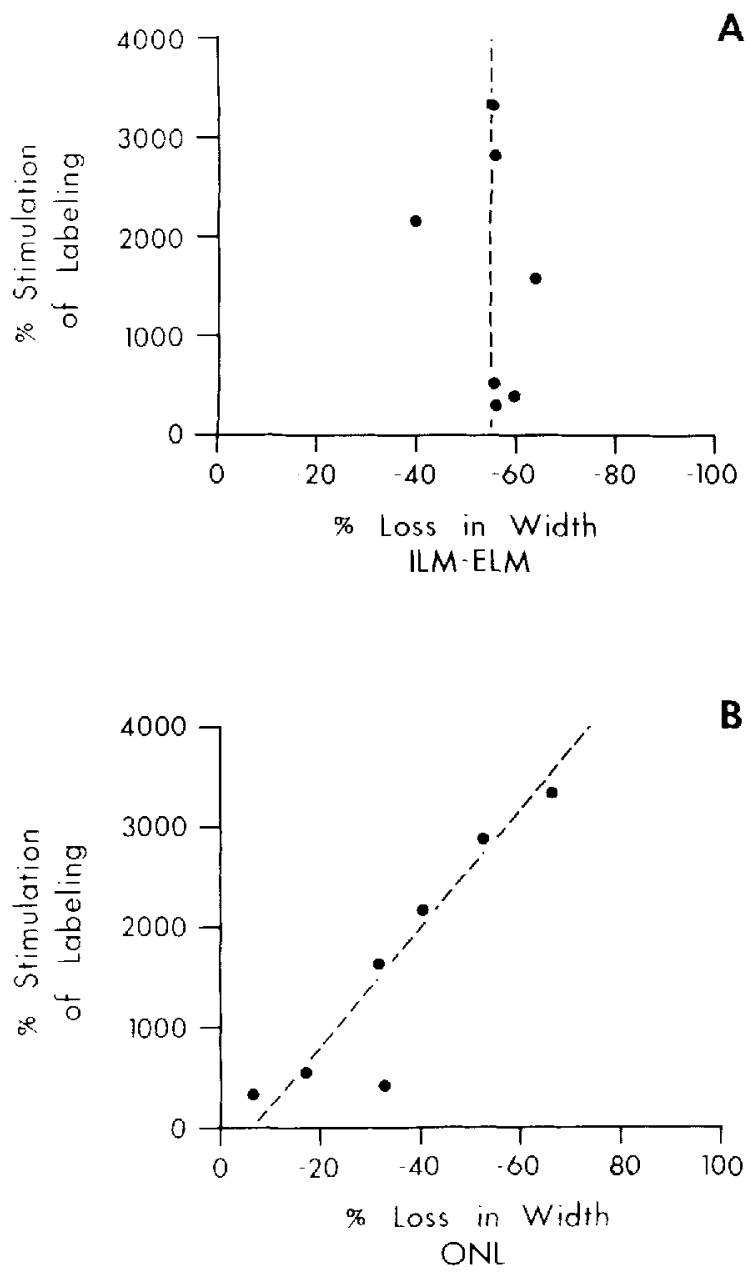

Fig. 12. Stimulation of ${ }^{3} \mathrm{H}$-thymidine incorporation related to retinal damage. On the abscissa is the percent loss in width of either the neural retina (measured from inner limiting membrane, ILM, to external limiting membrane, ELM) in panel $A$, or the outer nuclear layer (ONL) in panel $\mathrm{B}$, in the experimental, compared with the control, eyes of 7 fish at 4 weeks after injection of ouabain. On the ordinate is the percent difference in number of labeled cells between the two eyes. Each point is one fish. (A) The average loss in width of the retina (ILM to ELM) was $54.6 \%$ and is indicated by the vertical dashed line. (B) The stimulation of labeling was proportional to the degree of loss in width of the ONL. The dashed line is the least squares linear regression line (correlation coefficient, $r^{2}=0.917, p<0.01$ ).

layer. In fact, the outer nuclear layer of intact retinas contains a population of dividing cells called rod precursors (Sandy and Blaxter, 1980; Johns and Fernald, 1981). Rod precursors normally produce only rod photoreceptors, but do so throughout the life of the fish (Johns and Easter, 1977; Johns, 1982). Since they are the only mitotically active neuronal germinal cell in central retina, it 
seems quite reasonable to propose that rod precursors were the source of new neurons during regeneration. If this interpretation is correct, it suggests that the fate of these cells was altered, that is, they began to produce cells other than rods, only when the microenvironment surrounding them (i.e., the outer nuclear layer) was disrupted.

To destroy retinal neurons we used a method introduced by Wolburg and colleagues (Wolburg, 1975, 1976; Maier and Wolburg, 1979; Kurz-Isler and Wolburg, 1982) in which the cardiac glycoside, ouabain, is injected into the posterior chamber of the eye. We found that inner retinal layers were more susceptible than outer layers, as Maier and Wolburg (1979) observed previously. By injecting ${ }^{3} \mathrm{H}$-ouabain and processing the retinal tissues with a technique which allowed us to localize the radioactive ligand (Ernst and Mills, 1980), we showed that the gradient of damage matched the gradient of distribution of ${ }^{3} \mathrm{H}$-ouabain in the retina. The pattern of damage produced by this drug was fortuitous, since it allowed us to analyze the response of the retina after loss of cells in inner layers with sparing of photoreceptors in the outer nuclear layer and to compare this with the response after loss of inner layers as well as photoreceptors. We concluded that the response under the two conditions was different: no regeneration in the former case but only in the latter. Maier and Wolburg (1979) suggested that regeneration occurred no matter how severe the damage. This difference in interpretation is probably accounted for by the difficulty in achieving a consistent and reproducible level of retinal damage among a group of experimental fish. The dose-response curve for retinal damage as a function of the intraocular concentration of ouabain is steep (ranging from no cell loss to complete destruction of neural retina in less than half a decade; see Table 1), and methods for estimating intraocular concentrations are not very exact. This could have posed a problem in the interpretation of the results in the earlier study, since the fish were quite variable in size ( $7-8 \mathrm{~cm}$ and $10-12 \mathrm{~cm}$ body length). Each retina can be examined only once, so when one looks at a regenerating retina several weeks after injection, it is impossible to know precisely the state of degeneration at the start. In our experiments, we attempted to distinguish between regenerating and surviving photoreceptors using objective criteria based on length of cone ellipsoids and shape of rod outer segments. We chose these specific dimensions because we knew from an earlier study of photoreceptor differentiation in larval goldfish (Raymond, 1985) that these measures change significantly during maturation of photoreceptors in this species and therefore serve to indicate "age" of the photoreceptors. For cones, this method was reliable up to about 8 weeks, by which time regenerating cells began to approach the size and shape of mature cells. For rods, the population was restored more slowly, and substantial numbers of immature rods were observed in regenerating retinas up to 10 weeks and longer. Unfortunately, it was not possible to devise such a simple index of maturation for the other retinal cells. However, using ${ }^{3} \mathrm{H}$-thymidine autoradiography in conjunction with systematic observations of histological material including statistical tests for correlation, we were able to demonstrate with a high degree of confidence that regenerating cells in inner retinal layers were always accompanied by regenerating photoreceptors. This strongly suggests that regeneration was contingent upon loss of photoreceptors and that loss of cells in the inner layers was not sufficient. Furthermore, 
we had examples of retinas at each survival period up to 6 months in which inner retinal layers were missing but the outer nuclear layer was intact. Again this observation is consistent with the proposition that retinal regeneration did not occur unless the outer nuclear layer was damaged.

We believe that the most likely source of new cells in the regenerated retina is the population of rod precursors that are located in the outer nuclear layer of the teleost retina (Sandy and Blaxter, 1980; Johns and Fernald, 1981; Johns, 1982; Raymond and Rivlin, 1987). Previous studies noted that when the teleost retina was damaged, either by surgical removal of one quadrant (Lombardo, 1968, 1972), or by injection of ouabain (Maier and Wolburg, 1979; Kurz-Isler and Wolburg, 1982), or by injection of the catecholamine neurotoxin, 6-hydroxydopamine (Negishi et al., 1987), mitotic activity was enhanced in the outer nuclear layer.

The evidence that rod precursors are responsible for retinal regeneration can be summarized as follows.

1. Rod precursors survived after ouabain injection. This was shown by labeling rod precursors (and other dividing cells) in the intact retina with ${ }^{3} \mathrm{H}$-thymidine and following this with an injection of ouabain. Labeled rod precursors were found in the degenerated retina 1 week later. Rod precursors were lightly labeled, indicating that they had undergone repeated mitotic divisions during the 1-week interval, consistent with the idea that mitosis was stimulated in degenerating retinas (Lombardo, 1968, 1972; Maier and Wolburg, 1979; Negishi et al., 1987).

2. Regeneration of the retina occurred in scattered foci. In regenerating retinas scattered foci of mitotic cells were flanked by regions containing newly regenerated cells. The dividing cells appeared histologically similar to neuroepithelial cells, such as those in the circumferential germinal zone. Maier and Wolburg (1979) suggested that mitotic foci in the regenerating retina originated from cells migrating inward across the retina from the germinal zone at the retinal margin. We do not think this is likely, since their appearance in the retina did not follow a centripetal gradient as would be expected if they colonized the degenerated central regions from a source at the margin. Instead of a peripheral-central gradient, the neurogenic foci in the regenerating retina were scattered across the retina in much the same pattern as rod precursors in the intact retina (Johns, 1982).

3. Regeneration did not occur unless the outer nuclear layer was damaged. There are two lines of evidence to support this statement. First, in some retinas at all stages up to 6 months after ouabain injection, the outer nuclear layer was intact, and there was no obvious loss of photoreceptors, but the cellular laminae vitread to the outer nuclear layer were destroyed. Second, retinas that showed evidence of regeneration, judged by the presence of neurogenic foci and the stimulation of ${ }^{3} \mathrm{H}$-thymidine incorporation relative to the control eye, were those that had lost photoreceptors.

Other potential sources of germinal cells that might be involved in retinal regeneration include the retinal pigmented epithelium, the circumferential germinal zone, and Müller cells or Müller-associated cells in the inner nuclear layer. The pigmented epithelium has been implicated in retinal regeneration in amphibians (Keefe, 1973a,b; Reyer, 1977; Stroeva and Mitashov, 1981), but neither Lombardo $(1968,1972)$ nor Wolburg and colleagues (Maier and Wol- 
burg, 1979; Kurz-Isler and Wolburg, 1982) found evidence of enhanced mitotic activity or massive migration of pigmented epithelial cells into the degenerating teleost retina; nor did we see any.

As mentioned above, we did not observe a peripheral-central gradient of regeneration as might be expected if the germinal zone at the retinal margin contributed to retinal regeneration. However, mitotic activity was elevated in the germinal zone following ouabain injections (Maier and Wolburg, 1979; Kurz-Isler and Wolburg, 1982; and the present results). The time course of this mitotic stimulation was rapid, commencing within a day or less. This effect may have been triggered by growth factors associated with the wounding process (Ross et al., 1985), or it may have been a direct effect of ouabain (see later). We believe that mitotic activity in the germinal zone resulted in incremental peripheral growth of the retina but did not contribute to regeneration more centrally. In our preparations, even those which failed to regenerate, we observed an annulus of apparently normal retina adjacent to the retinal margin [Fig. 9(D)]. The width of the annulus (peripheral to central) was correlated with the amount of time that had elapsed since the ouabain injection (P. Raymond and R. Mangione-Smith, in preparation). The most likely interpretation is that this increment of new retina derived from the circumferential germinal zone was added to the retina as part of the normal growth process. It should therefore be considered "new" rather than "regenerated" retina. We have reason to believe that this was the case, since the fish, and their eyes, continued to grow normally after the ouabain injections. For example, the 3 fish killed 6 months after injection had grown from $3 \mathrm{~cm}$ standard length at the beginning of the experiment to an average of $4.4 \mathrm{~cm}$ at the end, and their lens diameters had increased from $1.5 \mathrm{~cm}$ (average for fish in the same experiment killed 7 days after injection) to $1.8 \mathrm{~mm}$ (average for the 3 fish killed at 6 months). At the end of the experiment, the experimental eye was the same size as the control eye, and retinal areas were approximately the same in both (P. Raymond and R. Mangione-Smith, in preparation). We conclude that the circumferential germinal zone continued to participate in peripheral growth of the retina but did not contribute to regeneration of central regions. In this we disagree with the interpretation put forth by Kurz-Isler and Wolburg (1982).

Another potential source of regenerating cells lies in the inner nuclear layer, where clusters of proliferating cells were seen at short intervals (within a day and throughout the first few weeks) after ouabain injection. However, these proliferating nests of cells appeared in partially damaged retinas and even in retinas with no obvious cell loss. Their identity is uncertain. One possibility is that they were Müller cells stimulated to divide by a direct effect of ouabain, rather than in response to events related to regeneration. Ouabain has been shown to be mitogenic for cultured flat cells (probably Müller-derived) from embryonic chick retina (Kaplowitz and Moscona, 1976). Furthermore, Müller cells in mammalian retina are stimulated to divide under certain pathological conditions such as hypoxia (Wilson et al., 1987) and proliferative diabetic retinopathy (Nork et al., 1987). However, we do not know whether the mitotic cells we observed at early stages following ouabain injections in teleost retinas were Müller cells. Immunocytochemical studies are in progress using Müllerspecific markers in combination with thymidine autoradiography to answer this question. 
Another possibility, which to us seems more likely, is that the mitotic cells in the inner nuclear layer derive from quiescent neuroblastic cells that may be retained in this layer after the retina matures. In larval and young juvenile goldfish, similar clusters of undifferentiated proliferating cells associated with Müller fibers are found in the inner nuclear layer (Johns, 1982; Raymond and Rivlin, 1987). These undifferentiated cells in the inner nuclear layer of the young larvae give rise to rod precursors that are later found in the outer nuclear layer of juveniles and adults. During postembryonic development these proliferating cells migrate from inner to outer nuclear layer, along the radial processes of Müller cells (Raymond and Rivlin, 1987). They do not produce neurons in the inner nuclear layer, nor do they seem to generate Müller cells, at least in the intact retina (Raymond and Rivlin, 1987). It is possible that a few of these cells persist in the juvenile retina and are stimulated to divide in ouabain-damaged retinas, and they may even contribute to the regeneration process. If they do, it would hardly alter our hypothesis that rod precursors are the source of regenerated cells, since these undifferentiated cells in the inner nuclear layer normally belong to the rod lineage.

The question arises as to whether the regenerated retina is functional. Stuermer, in collaboration with Wolburg (Stuermer et al., 1985), showed that optic axons from regenerated goldfish retinas grew back into the optic tectum, and Kastner and Wolburg (1982) demonstrated recovery of visual function using a visual reflex: optokinetic nystagmus.

To summarize, we believe the following events take place in goldfish retinas following intravitreal administration of ouabain. First, mitotic activity is stimulated in proliferating cells, including rod precursors, undifferentiated cells probably associated with Müller fibers, and germinal cells at the margin. The initial effect is independent of the degree of retinal damage and may result from a nonspecific mitogenic stimulus by ouabain or from degenerating cellular debris. Second, degeneration of retinal cells proceeds from the inside (vitread) outward, eventually involving photoreceptors. Third, in those cases in which photoreceptors are spared, the inner layers fail to regenerate and contain only Müller cells and some horizontal cells which survive. If the outer nuclear layer is damaged and photoreceptors are destroyed, the retina regenerates. Müller cells appear to survive or at least are present during the earliest phases of regeneration, although the role they play, if any, is unclear. Beginning at 2-4 weeks new retinal neurons are generated through mitotic divisions of germinal cells located in foci scattered across the retina. Our evidence supports the idea that these neurogenic foci are derived from mitotic rod precursors present in the outer nuclear layer of intact growing retinas. Until we have a specific marker for rod precursors, however, this conclusion rests on correlative evidence only.

The implication of these results is that the fate of rod precursors is altered under conditions in which the retina regenerates. It has not been shown that rod precursors are committed stem cells, although under normal circumstances they give rise exclusively to rods (Johns, 1982; Raymond and Rivlin, 1987). It could be that the progeny of rod precursors are normally directed to differentiate into rods (or are prevented from becoming anything else) by signals in the local environment of the outer nuclear layer. This interpretation is attractive because it offers an explanation as to why regeneration is contin- 
gent upon disruption of the outer nuclear layer and loss of photoreceptor cells. We think it is especially noteworthy that the neurogenic foci in the regenerating retina are directly apposed to the external limiting membrane (the former ventricular surface) and the inner limiting membrane with its accompanying basal lamina. Neuroepithelial cells in the circumferential growth zone have a similar configuration. Rod precursors in the intact retina, in contrast, have lost their attachment at both surfaces (Raymond and Rivlin, 1987). The signal that triggers rod precursors to alter their lineage restrictions and return to a pluripotent state might be contact with one or the other surface. Recent studies by Reh and coworkers (1987) suggest that contact with the basal lamina (vascular membrane) may trigger metaplasia (transdetermination) of migratory pigmented epithelial cells in the devascularized, degenerated amphibian retina (Reh and Nagy, 1987). Upon contact with this membrane, or perhaps more specifically with the laminin that it contains (Reh et al., 1987), pigmented epithelial cells become depigmented, begin to proliferate, and give rise to a germinative neuroepithelium from which the neural retina regenerates. Similar signals might control the determination of rod precursors in the teleost retina.

The factors controlling neuronal differentiation are not well understood in any system. Growth factors, such as NGF (nerve growth factor; Levi-Montalcini, 1982) and cholinergic conditioning factor (Patterson, 1978; Fukada, 1980), have been implicated in some systems. Cellular interactions play a role in other cases (Doe and Goodman, 1985). Recent work in fish (Negishi et al., 1982, 1987) and frogs (Reh and Tully, 1986; Reh, 1987) has suggested that feedback from differentiated neurons may regulate the rate of production of specific types of new retinal neurons in the circumferential germinal zone. In these experiments, 6-hydroxydopamine (Negishi et al., 1982, 1987; Reh and Tully, 1986) or kainic acid (Reh, 1987; Negishi, personal communication) was injected intraocularly to selectively destroy specific populations of retinal neurons. The germinal zone at the ciliary margin responded by increasing its rate of production of those specific classes of cells that had been lost. The production of other cell types continued at control levels. Nothing is known about the mechanism of regulation involved in these experiments, not even whether there are committed stem cell lines for various retinal cell types within the germinal zone that are selectively affected, or whether there is one pluripotent stem cell line and the spectrum of progeny it produces is altered. The situation in the ouabain-treated goldfish retina differs in that an identified class of cell-specific progenitor is affected, the rod precursors, whose progeny are restricted to the rod lineage in the intact retina. In the regenerating retina, these cells are induced (or permitted) to express a wider range of potential fates, but only after the differentiated photoreceptors around them are destroyed. Our goal now is to discover what triggers this alteration in cell determination.

We thank Ms. Beverly Clendening and Ms. Janet Braisted for technical assistance and Ms. Linda Barthel for photography. Mrs. Sharon Moskwiak typed the manuscript. Special thanks to Dr. Stephen A. Ernst for assistance with the ${ }^{3} \mathrm{H}$-ouabain experiment and for the use of his freezedrying apparatus. Dr. Stephen S. Easter, Jr. graciously provided his translation from the Italian of the two papers by Lombardo. This research was supported by NIH grant EY04318 and a Sloan Foundation Fellowship to P.A.R. 


\section{REFERENCES}

Cleaver, J. E. (1967). Thymidine Metabolism and Cell Kinetics, Frontiers in Biology, A. Neuberger and E. L. Tatum (Eds.), North Holland, Amsterdam, Vol. 6.

Davson, H. (1980). Physiology of the Eye, 4th ed., Academic Press, New York.

Doe, C. O., and Goodman, C. S. (1985). Early events in insect neurogenesis. II. The role of cell intractions and cell lineage in the determination of neuronal precursor cells. Develop. Biol. 111:206-219.

Easter, S. S., Johns, P. R., and BaumanN, L. R. (1977). Growth of the adult goldfish eye. I. Optics. Vis. Res. 17:469-477.

Easter, S. S., Mangione, R., and Malinoski, C. (1986). Regeneration of the goldfish retina. Invest. Ophthalmol. Vis. Sci. (Suppl.) 27:206.

ERNST, S. A., and MILLS, J. W. (1980). Autoradiographic localization of tritiated ouabain-sensitive sodium pump sites in ion transporting epithelia. J. Histochem. Cytochem. 28:72-77.

FUKADA, K. (1980). Hormonal control of neurotransmitter choice in sympathetic neuron cultures. Nature 287:535-555.

JoHNS, P. R. (1982). The formation of photoreceptors in the growing retinas of larval and adult goldfish. J. Neurosci. 2:179-198.

JoHNS, P. R., and EASTER, S. S. (1977). Growth of the adult goldfish eye. II. Increase in retinal cell number. J. Comp. Neurol. 176:331-342.

Johns, P. R., and FErnaLd, R. D. (1981). Genesis of rods in teleost fish retina. Nature 293:141142.

KaPlowitz, P. B., and MosconA, A. A. (1976). Stimulation of DNA synthesis by ouabain and concanavalin A in cultures of embryonic neural retina cells. Cell Different. 5:109-119.

KASTNER, R., and WolbuRG, H. (1982). Functional regeneration of the visual system in teleosts. Comparative investigations after optic nerve crush and damage of the retina. $Z$. Naturforsch. 37:1274-1280.

KEEFE, J. R. (1973a). An analysis of urodelian retinal regeneration: I. Studies of the cellular source of retinal regeneration in Notophthalmus viridescens utilizing ${ }^{3} \mathrm{H}$-thymidine and colchicine. J. Exp. Zool. 184:185-206.

KEEFE, J. R. (1973b). An analysis of urodelian retinal regeneration: IV. Studies of the cellular source of retinal regeneration in Triturus cristatus carnifex using ${ }^{3} \mathrm{H}$-thymidine. J. Exp. Zool. 184:239-258.

KURZ-ISLER, G., and WolBuRG, H. (1982). Morphological study on the regeneration of the retina in the rainbow trout after ouabain-induced damage: Evidence of dedifferentiation of photoreceptors. Cell Tiss. Res. 225:165-178.

La Vail, M. M., Gorrin, G. M., RePaci, M. A., Thomas, L. A., and Ginsberg, H. M. (1987). Genetic regulation of light damage to photoreceptors. Invest. Ophthalmol. Vis. Sci. 28:10431048.

Levi-Montalcini, R. (1982). Developmental neurobiology and the natural history of nerve growth factor. Ann. Rev. Neurosci. 5:341-362.

Lombardo, F. (1968). The regeneration of the retina in the adult teleost (in Italian). Accad. Lincei-Rend. Cont. Sci. Fis. Mat. e. Nat. 45:631-635.

LOMBARDO, F. (1972). Course and localization of mitoses during the regeneration of the retina of an adult teleost (in Italian). Accad. Lincei-Rend. Cont. Sci. Fis. Mat. e. Nat. 53:323-327.

MaIER, W., and WolburG, H. (1979). Regeneration of the goldfish retina after exposure to different doses of ouabain. Cell Tiss. Res. 202:99-118.

MCGRAIL, K. M., and SwEADNER, K. J. (1986). Immunofluorescent localization of two different $\mathrm{Na}, \mathrm{K}-\mathrm{ATPases}$ in the rat retina and in identified dissociated retinal cells. $J$. Neurosci. 6:12721283.

Negishi, K., TERanishi, T., and KaTo, S. (1982). New dopaminergic and indoleamine-accumulating cells in the growth zone of goldfish retinas after neurotoxic destruction. Science 216:747-749.

Negishi, K., Teranish, T., Kato, S., and Nakamura, Y. (1987). Paradoxical induction of dopaminergic cells following intravitreal injection of high doses of 6-hydroxydopamine in juvenile carp retina. Develop. Brain Res. 33:67-69.

Nork, T. M., Wallow, I. H. L., Sramek, S. J., and Anderson, G. L. (1987). Müller cell involvement in proliferative diabetic retinopathy. Invest. Ophthalmol. Vis. Sci. (Suppl.) 28:123.

PatTerson, P. H. (1978). Environmental determination of autonomic neurotransmitter functions. Ann. Rev. Neurosci. 1:1-17. 
RAYMOND, P. A. (1985). Cytodifferentiation of photoreceptors in larval goldfish: Delayed maturation of rods. J. Comp. Neurol. 236:90-105.

RAYMOND, P. A. (1986). Movement of retinal terminals in goldfish optic tectum predicted by analysis of neuronal proliferation. J. Neurosci. 6:2479-2488.

RAYMOND, P. A. (1987). Progenitor cells in outer nuclear layer of goldfish retina that normally produce only rods produce other neurons during retinal regeneration. Invest. Ophthalmol. Vis. Sci. (Suppl.) 28:288.

Raymond, P. A., Reifler, M. J., Rivi.in, P. K., and Clendening, B. (1986). Progenitor cells specific for rods lose their specificity in regenerating goldfish retina. Soc. Neurosci. Abst. 12:118.

RAYMOND, P. A., and RivLIN, P. K. (1987). Germinal cells in the goldfish retina that produce rod photoreceptors. Dev. Biol. 122:120-138.

REH, T. A. (1987). Cell-specific regulation of neuronal production in the larval frog retina. $J$. Neurosci. 7:3317-3324.

REH, T. A., and TULLY, T. (1986). Regulation of tyrosine hydroxylase-containing amacrine cell number in larval frog retina. Dev. Biol. 114:463-469.

REH, T. A., and NAGY, T. (1987). A possible role for the vascular membrane in retinal regeneration in Rana catesbienna tadpoles. Dev. Biol. 122:471-482.

REH, T. A., NAGY, T., and GRETTON, H. (1987). Retinal pigmented epithelia cells induced to transdifferentiate to neurons by laminin. Nature 330:68-71.

REYER, R. W. (1977). The amphibian eye: Development and regeneration. In Handbook of Sensory Physiology, Vol. 7/5, The Visual System in Vertebrates, F. Crescitelli (Ed.), Springer-Verlag, New York, pp. 309-390.

RIVLIN, P. K., and RAYMOND, P. A. (1987). Use of osmium tetroxide-potassium ferricyanide in reconstructing cells from serial, ultrathin sections. $J$. Neurosci. Meth. 20:23-33.

Ross, R., Bowen-Pope, D. F., and RaInes, E. W. (1985). Platelet-derived growth factor: Its potential roles in wound healing, atherosclerosis, neoplasia and growth and development. In Ciba Foundation Symposium 116, Growth Factors in Biology and Medicine, D. Evered, J. Nugent, and J. Whelan (Eds.), London, Pitman, pp. 98-112.

SANDY, J. M., and BLAXTER, J. H. S. (1980). A study of retinal development in larval herring and sole. J. Mar. Biol. Assoc. UK 60:59-71.

Schwartz, A., Lindenmayer, G. E., and Allen, J. C. (1975). The sodium-potassium adenosine triphosphatase: Pharmacological, physiological and biochemical aspects. Pharmacol. Rev. 27:3-134.

Sharma, S. C., and Ungar, F. (1980). Histogenesis of the goldfish retina. J. Comp. Neurol. 191:373-382.

SiEGEL, S. (1956). Nonparametric Statistics, McGraw-Hill, New York.

STAHL, W. L., and BASKIN, D. G. (1984). Immunocytochemical localization of $\mathrm{Na}^{+}, \mathrm{K}^{+}$adenosine triphosphatase in the rat retina. J. Histochem. Cytochem. 32:248-250.

STIRLING, C. E., and LEE, A. (1980). [ $\left.{ }^{3} \mathrm{H}\right]$ ouabain autoradiography of frog retina. J. Cell. Biol. 85:313-324.

Stroeva, O. G., and Mitashov, V. I. (1981). Developmental potential of vertebrate eye tissues: Regeneration of retina and lens. In Problems of Developmental Biology, N. Krushcov (Ed.), MIR Publishers, Moscow, pp. 168-207.

Stuermer, C. A. D., NiepenberG, A., and Wolburg, H. (1985). Aberrant axonal paths in regenerated goldfish retina and tectum following intraocular injection of ouabain. Neurosci. Lett. 58:333-338.

WALLs, G. L. (1967). The Vertebrate Eye and Its Adaptive Radiation, Hafner, New York.

Wilson, C. A., STefansson, E., SChofn, T., and Kuwabara, T. (1987). Mitosis in the adult rat retina after temporary interruption of retinal blood flow. Invest. Ophthalmol. Vis. Sci. (Suppl.) 28:107.

WolbuRG, H. (1975). Time- and dose-dependent influence of ouabain on the ultrastructure of optic neurones. Cell Tiss. Res. 164:503-517.

WolBURG, H. (1976). Influence of ouabain on the fine structure of teleost retina. Acta Neuropathol. 34:255-266. 